This item was submitted to Loughborough's Research Repository by the author.

Items in Figshare are protected by copyright, with all rights reserved, unless otherwise indicated.

\title{
Common cycles and common trends in the stock and oil markets: Evidence from more than 150 years of data
}

PLEASE CITE THE PUBLISHED VERSION

http://dx.doi.org/10.1016/j.eneco.2016.11.003

\section{PUBLISHER}

(c) Elsevier

\section{VERSION}

AM (Accepted Manuscript)

\section{PUBLISHER STATEMENT}

This work is made available according to the conditions of the Creative Commons Attribution-NonCommercialNoDerivatives 4.0 International (CC BY-NC-ND 4.0) licence. Full details of this licence are available at: https://creativecommons.org/licenses/by-nc-nd/4.0/

\section{LICENCE}

CC BY-NC-ND 4.0

\section{REPOSITORY RECORD}

Balcilar, Mehmet, Rangan Gupta, and Mark E. Wohar. 2019. "Common Cycles and Common Trends in the Stock and Oil Markets: Evidence from More Than 150 Years of Data". figshare. https://hdl.handle.net/2134/26058. 


\title{
Common cycles and common trends in the stock and oil markets: Evidence from more than 150 years of data*
}

\author{
Mehmet Balcilar \\ Eastern Mediterranean University, Turkey \\ and \\ University of Pretoria, South Africa \\ mehmet@mbalcilar.net \\ Rangan Gupta \\ University of Pretoria, South Africa \\ Rangan.Gupta@up.ac.za \\ Mark E. Wohar \\ University of Nebraska-Omaha, USA \\ mwohar@mail.unomaha.edu \\ and \\ Loughborough University, UK
}

August 2, 2016

Key words: Oil market, Stock market, Common Cycles, Common Features, Trend-cycle decomposition, Permanent and transitory shocks.

JEL: C22, F31

\footnotetext{
* We would like to thank Professor Alain Hecq, Professor João Victor Issler and Professor Farshid Vahid for providing us with some of the GAUSS codes used in the empirical analysis of the paper. In addition, we would like to thank two anonymous referees for many helpful comments. However, any remaining errors are solely ours.
} 


\begin{abstract}
This paper investigates the role of permanent and transitory shocks, within the framework of common cycles and common trends, in explaining stock and oil prices. We perform a multivariate variance decomposition analysis of monthly data on the West Texas Intermediate (WTI) oil price and the S\&P500. The dataset used in the study spans a long period of 150 years and therefore contains a rich history to examine both the short- and longrun comovement properties of oil and stock prices. Given that the oil and stock markets might comove both in the short- and long-run, it is of interest to see the relative impacts of transitory and permanent shocks on both variables. We find that (log) oil price and (log) S\&P 500 share a common stochastic trend for our full sample of September 1859 to July 2015, but a common cycle only exists during the post-WW II period. Full and post-WW II samples have quite different common feature estimates in terms of the impact of permanent and transitory shocks as measured by the impulse responses and forecast error variance decompositions. We also find that in the short-run oil is driven mostly by cycles (transitory shocks) and stock market is mostly driven by permanent shocks. But, permanent shocks dominate in the long-run.
\end{abstract}




\section{Introduction}

There exists a sizeable large literature that connects movements in oil returns and its volatility with recessions and inflationary episodes in the US economy ${ }^{1}$ According to Hamilton (2008), nine of ten recessions in the US since World War II have been preceded by an increase in oil price. In fact, Hamilton (2009) even goes so far as to argue that a large proportion of the recent downturn in the US during the "Great Recession" can also be attributed to the oil price shock of 2007-2008. In the same vein, there is also a large literature that relates to the link between stock prices and economic activity, dating as far back as Mitchell and Bums (1938). ${ }^{2}$ Unlike the empirical literature investigating oil, the impact of stock returns on US recessions is however, mixed, with more recent studies, based on sophisticated econometric techniques, pointing towards its role in predicting economic activity. ${ }^{3}$ Besides the large in-sample literature (see Footnotes 1 and 2) Stock and Watson (2003), and Rapach and Weber (2004), Kilian and Vigfusson (2011, 2013) provide evidence of the role of oil and the stock market in forecasting output growth and inflation for the US economy. Finally, financial historians, like Ahamed (2009) and Ferguson (2008), have suggested that financial crises are often preceded by bubbles in the asset and commodity markets, which, in turn is vindicated by Phillips and Yu (2011) based on formal tests of bubble detection in real-time.

\footnotetext{
${ }^{1}$ See for example, Rasche and Tatom (1977), Mork and Hall (1980), Hamilton (1983, 2011), and Hickman et al. (1987), Balke et al., (2002, 2010), Brown and Yücel (2002), Barsky and Kilian (2004), Jones et al. (2004), Kilian (2008a,b, 2009a,b), Elder and Serletis (2010), Nakov and Pescatori (2010), Baumeister and Peersman (2013a,b), Kang and Ratti (2013a, b), Antonakakis et al., (2014a), Bjørnland and Larsen (2015), and Baumeister and Kilian (2015), and references cited therein..

${ }^{2}$ More recent studies followed, and includes that of of Fischer and Merton (1984), Barro (1990), Fama (1981, 1990), Harvey (1989), Stock and Watson (1989), Choi et al (1999), Schwert (1990), Estrella and Mishkin (1998), Colombage (2009), Nyberg (2010), Mili et al (2012), and Erdogan et al., (2015).

${ }^{3}$ Interestingly, Campbell et al (2001) proposes that the variance of stock returns, rather than the returns themselves, have predictive content for output growth. Campbell (2001) finds evidence of high equity price volatility in one quarter to signal low macroeconomic growth in the next.
} 
In addition, following the early works of Chen et al. (1986), Jones and Kaul (1996) and Sadorsky (1999), there exists a huge, and still growing, literature that relates short and longrun movements in oil and stock markets (for a detailed literature review in this regard, see for example, Kilian and Park (2009), Apergis and Miller (2009), Balcilar and Ozdemir (2012), Antonakakis and Filis (2013), Kang and Ratti (2013b), Antonakakis et al., (2014a, b), Broadstock and Filis (2014), Balcilar et al., (2015), Narayan and Gupta (2015), Angelidis et al., (forthcoming), Kang et al., (forthcoming), and references cited therein). While, the early literature primarily treated oil price as exogenous (supply-side shocks); following Kilian’s (2009) seminal work which highlighted the endogeneity of oil price movements by relating it to economic activity, the recent studies on the oil and stock market relationship treats bothe variables as endogenous.

Relating the three (oil and macroeconomic variables, stock market and the economy, and oil and stock markets) strands of literature mentioned above, we can draw the following conclusions: (a) Whether it is based on in-sample or out-of-sample evidence, the importance of the role played by the stock and oil markets for the US economy is, in general, undeniable, and; (b) Oil and stock markets affect each other in both short and long-runs.

Against this backdrop, the objective of this paper is to investigate the role of permanent (i.e., aggregate supply shocks, such as technology shocks) and transitory shocks (namely, aggregate demand shocks, such as those resulting from changes in interest rate, inflation, fiscal policy, taste, velocity, and autonomous investment), within the framework of common cycles and common trends, in explaining stock and oil price movements, with both variables being treated as endogenous. Given that oil and stock prices act as leading indicators for the US economy, it is of paramount importance for a policy maker to determine what types of 
shocks drives these two markets. In other words, detecting whether these shocks are temporary or permanent in nature would help in better policy design. Elaborating further on this issue, we can say that, only if temporary shocks are driving the two markets, can a policy maker have a role in affecting oil and stock prices. So for instance, if there are possible persistent bubbles in these two markets, and its collapse is likely to affect the economy negatively due to the leading role played by these two prices, the policy maker can change monetary or fiscal policy to correct for possible adverse effects.

While, applications of the common cycles and common trends methods to stock markets across and within countries can be found in Narayan (2011) and Narayan and Thuraisamy (2013) respectively, ${ }^{4}$ to the best of our knowledge, this is the first study to determine the nature of shocks that drives these two markets simultaneously. ${ }^{5}$ For our purpose, we perform a multivariate variance decomposition analysis of monthly data on the West Texas Intermediate (WTI) oil price and the S\&P500 starting in September, 1859 (1859:09) to July, 2015 (2015:07), using Vahid and Engle’s (1993) approach to identify common trends and cycles in the context of the multivariate Beveridge and Nelson (1981) decomposition technique. ${ }^{6}$ Another unique feature of our analysis is that sample period runs from the beginning of the modern era of the petroleum industry with the drilling of the first oil well on August 27, 1859 in Titusville, Pennsylvania.

\footnotetext{
${ }^{4}$ Narayan (2011) looks at comovements between stock prices of emerging economies: Singapore, Taiwan, and South Korea, while Narayan and Thuraisamy (2013) analyzed comovements between stock prices within the US equity markets (S\&P 500, Dow Jones and the NASDAQ).

${ }^{5}$ Other applications of common cycles and common trends methodology in business cycles (national, local and sectoral), macroeconomic variables, health expenditures, metals and commodities can be found in the papers, such as: Vahid and Engle (1993), Engle and Issler (1995), Issler and Vahid (2001), Narayan (2008), Narayan and Narayan (2008a, b), and Issler et al., (2014).

${ }^{6}$ Common trends and cycles can also be introduced into the multivariate structural time series model of Harvey (1989) and Koopman et al. (2000).
} 
Note that, a multivariate approach introduces the possibility that trends and cycles may be common among variables. Engle and Kozicki (1993) defines a common feature to exist if a linear combination of the series fails to have the feature even though each of the series individually has the feature. While, cointegration is a common feature, another common feature of interest is the presence of common serial correlation patterns, i.e., common cycles. Issler and Vahid (2001) pointed out that the joint modeling of common-trend and commoncycle restrictions to identify permanent and transitory shocks has a clear advantage over the use of common-trend restrictions only. Understandably, if common-cycle restrictions are correctly imposed, estimates of the dynamic model (traditionally, a vector autoregression (VAR) model) are more precise, and leads to more accurate measurement of the relative importance of permanent and transitory shocks.

Our approach consists of four steps: First, we perform a battery of unit root tests (without and with breaks) on the WTI oil and S\&P500 stock prices to establish the integration property of the data series. Second, we investigate the existence of common trends (i.e. co-movement over the long run) by applying the Johansen $(1988,1991)$ maximum likelihood techniques, and the multivariate cointegration method of Stock and Watson (1988a). Third, we examine the existence of common cycles (i.e. co-movement over the short run), by using the following test statistics: Weak Form (WF) reduced ranked structure test (Hecq et al. 2000, 2002, 2006); Serial Correlation Common Features (SCCF) (Engle and Kozicki, 1993; Vahid and Engle, 1993), and; Polynomial Serial Correlation Common Features (PSCCF) (Cubadda and Hecq, 2001, 2003). Finally, we conduct multivariate variance decomposition and impulse response analyses to examine the relative importance of permanent and transitory innovations in explaining variations in WTI oil and S\&P500 stock prices. Note that, though not the primary goal of the paper, but once we identify the common trend and common cycle amongst these 
two variables, we are also able to decipher the role played by oil and stock prices in driving these two common features.

Common features estimation approach introduced previously in the literature (e.g., Engle and Kozicki, 1993; Vahid and Engle, 1993; Issler and Vahid, 2001) require that some linear combinations formed from the first differences of the cointegrated I(1) time series be white noise and, hence, the co-movements be contemporaneous. There is indeed a quite strong assumption that does not consider other possible co-cycle structures. Another restrictive feature of the previous approaches is that they require that the short- and long-run comovements be generated from the same common factors. Common features estimation methods used in this paper have three advantages. First, based on the PSCCF (Cubadda and Hecq, 2001, 2003) approach we allow for non-contemporaneous common cyclical movements among the I(1) time series. Second, the WF structure used in the paper (Hecq et al. 2000, 2002, 2006) allows for the presence of short- and long-run comovements that are generated from different factors. A third advantage of our approach compared to the previous approaches is the flexibility to allow for imposing the implied common trends and common features reduced rank structures on the estimated model. Finally, the existence of cointegration as well as the permanent and cyclical components in each series allows one to conduct more accurate long-run forecasts (relative to the traditional VAR models) of the variables in question. One is also to determine the cycle of each series once the permanent component is extracted. Furthermore, the finding of a common stochastic trend between oil prices and stock prices should be the long-run economic growth that will set the growth rate of both the oil and stock prices. The changes in the long-run economic growth rate will induce long-run comovement of both oil and stock market prices. Furthermore, the finding of 
cocycling behavior between oil and stock markets indicates to what extent a transitory shock in one market is transmitted to the other market.

The remainder of the paper is organized as follows: Section 2 presents the methodology, with Section 3 discussing the data and the results. Section 4 concludes the paper with policy recommendations.

\section{Methodology}

The major focus of this study is to examine the short- and long-run comovement of oil and stock prices. The dataset used in the study spans a long period of 150 years and therefore has a quite rich history to examine both the short- and long-run comovement properties of oil and stock prices. There are various channels that may lead to short-run or cyclical comovement and long-run comovement (co-trending) of these series. A large number of papers discussed in the introduction find evidence that increases in oil prices may lead to recessions and falling stock prices, resulting in cocycles. The long-run growth trends in the market value of firms will drive both stock prices and oil prices through resulting economic growth.

Long-run comovement among nonstationary time series require these series to be cointegrated and implies that their long-run tendencies are driven by some common stochastic trends. Common stochastic trends lead to the comovement of the low frequency (permanent) components of the series. The long-run comovement of the oil and stock markets then requires oil and sock price be cointegrated. Long-run comovement is derived by common stochastic trend shared by both the oil and stock prices. The reason behind this common stochastic trend should be the long-run economic growth that will set the growth 
rate of both the oil and stock prices. The changes in the long-run economic growth rate will induce long-run comovement of both oil and stock market prices.

However, oil and stock markets might also comove in the short-run. This means that deviations of these series from their long-run common trends also comove leading to cocycling behavior. A large number of papers discussed in Section 1 documented this cocycling behavior based on various econometric methods. The short-run comovement behavior relates to the high frequency (temporary) components of the series and thus usually referred as "cocycles". The cocycling behavior of oil and stock prices might be due to business cycles, wars, common structural breaks (co-breaks), volatility spillovers, etc. Cocycling behavior between oil and stock markets show to what extent a transitory shock in one market is transmitted to the other market.

\subsection{Cointegration and common trends}

Both the short- and long-run comovements of economic time series involve various challenges in terms of empirical modeling. The existence of common stochastic trends or cointegration among economic time series is one of the well-known stylized facts. Some stationary linear combinations of the I(1) series do not have the stochastic trend property that each I(1) series has since cointegration vectors annul these stochastic trends. Engle and Kozicki (1993) define this as a "common feature”. A feature is a common feature, if each of the series has the feature but a linear combination of the series fails to have this feature.

Analogous to common stochastic trends, Engle and Kozicki (1993) introduced a notion of serial correlation common features (SCCF). A group of time series will have an SCCF structure, if each series has serial correlation, but a linear combination of the series is serially 
uncorrelated or an innovation process with respect to the past information set. Serial correlation signifies a (persistent) cyclical feature in the level of each series, but when the cyclical feature is common to each series, we will be able to find linear combinations of the cyclical component of each series that does not have the cyclical feature.

Our empirical investigation first tests for common-trends and common cycles. Then, we estimate reduced rank regression (RRR) models imposing the common trends and common cycles features. Common trend and cycle components are also estimated. The estimated restricted models are used to decompose both series into their permanent and transitory (PT) components. Finally, we obtain impulse responses (IR) and forecast error variance decompositions (FEVD) of permanent and transitory shocks.

In order to explain the relevant concepts, we focus on the following Wold representation of the vector error correction model (VECM) (Engle and Granger, 1987; Johansen, 1988, 1991):

$$
\Delta Y_{t}=C(L) \varepsilon_{t}
$$

where and $\varepsilon_{t}$ is a multivariate Gaussian white noise process with 0 mean and nonsingular covariance matrix $\Sigma, \varepsilon_{t} \sim N(0, \Sigma)$ and $C(L)=I_{n}+\sum_{i=1}^{\infty} C_{i} L^{i}$. The VECM (1) can be written as $\Delta Y_{t}=\Pi Y_{t-1}+\sum_{i=1}^{p-1} \Gamma_{i} \Delta Y_{t-i}+\varepsilon_{t}$, where $\Pi$ has rank $r<n$ and, thus, there exist $n \times r$ matrices $\alpha$ and $\beta$ such that $\Pi=\alpha \beta^{\prime}$. Stock and Watson (1988b) show the existence of the well-known common trends representation:

$$
Y_{t}=C(1) \xi_{t}+C^{*}(L) \varepsilon_{t}
$$

where $\xi_{t}=\sum_{s=1}^{t} \varepsilon_{s}, \quad \varepsilon_{0}=0$ for $i \leq 0$ and $C^{*}(L)=(1-L)^{-1}[C(L)-C(1)]=\sum_{i=0}^{\infty} C_{i}^{*} L^{i}$ with $C_{i}^{*}=-\sum_{j=i+1}^{\infty} C_{j}$. Equation (2) is the multivariate Beveridge-Nelson (1981) (BN) 
decomposition of $Y_{t}$. In this case, a nonsingular matrix $\Lambda$ exists such that $C(1) \Lambda=\left[\begin{array}{ll}H & 0_{n \times r}\end{array}\right]$, where $H$ is an $n \times k$ matrix with full column. Using the matrix $\Lambda$ we can show that

$$
\begin{aligned}
Y_{t} & =H \tilde{\tau}_{t}+\psi_{t} \\
& =\tau_{t}+\psi_{t}
\end{aligned}
$$

where $\tau_{t}=H \tilde{\tau}_{t}$ and $\tilde{\tau}_{t}$ are the first $k$ components of $\Lambda^{-1} \xi_{t}=\Lambda^{-1} \sum_{s=1}^{t} \varepsilon_{s}$ and $H$ is an $n \times k$ matrix with full column rank matrix with full column rank. Equation (3) show that the linear cointegration combinations are linear combinations of the transitory or cyclical components. This shows the relationship between the multivariate BN decomposition, common trends, and cyclical components arising from a VECM.

\subsection{Common features and common-cycles}

We will examine three notions of common cycles which imply that some form of reduced rank restriction can be imposed on the VECM in (1) leading to fewer number of terms in $C^{*}(L) \varepsilon_{t}$ and therefore each of the $n$ transitory components in $\psi_{t}$ can be obtained as a linear combination of less than $n$ cyclical components.

The first of such common cycle notion is the serial correlation common features (SCCF) of Engle and Kozicki (1993) and Vahid and Engle (1993). ${ }^{7}$ The SCCF imposes the reduced rank restrictions on $\Delta Y_{t}$, because they describe the short-run movements of all the terms relating to the $\Delta Y_{t}$ given in VECM in Equation (1). A second notion of common cycles that we consider is the polynomial serial correlation common features (PSCCF) of Cubadda and Hecq (2001, 2003). The PSCCF specification does not require contemporaneous synchronization among the cycles in order to reduce to number of cyclical components and allows some cycles to lead or lag the others. The third notion of common cycles is the weak form serial correlation

\footnotetext{
${ }^{7}$ Hecq et al. (2000, 2002, 2006) also define a similar notion with less restrictive conditions and, therefore, refer the SCCF as the strong form (SF).
} 
common features (WF) of Hecq et al. (2000, 2002, 2006). The WF applies to $\Delta Y_{t}$ in deviations from the error correction terms $\alpha \beta^{\prime} Y_{t-1}$, i.e., $\Delta Y_{t}-\alpha \beta^{\prime} Y_{t-1}$, so it requires both $\Delta Y_{t}$ and $\alpha \beta^{\prime} Y_{t-1}$ have the same serial correlation structure.

Engle and Kozicki (1993) introduced the notion of SCCF and Vahid and Engle (1993) further generalized and presented statistical inference. The notion of SCCF implies that a vector of serially correlated stationary time series move together in such a way that some linear combinations of these series exists, which are a serially uncorrelated vector of white noise processes. Applied to the VECM in equation (1), the series $\Delta Y_{t}$ has SSCF, if there exists an $n \times s$ matrix $\delta_{S}$ such that (1) $\delta_{S}^{\prime} \alpha=0$ and (2) $\delta_{S}^{\prime} \Gamma_{i}, i=1,2, \ldots, p-1$, on the VECM in equation (1).

A drawback of the SCCF is the requirement that the common cycles must be contemporaneously synchronized. In this case, there will be no lead or lag relationship among the common cyclical components. The PSCCF relaxes this assumption and allows common serial correlations among the non-contemporaneous elements.

Introduced by Cubadda and Hecq (2001, 2003), the notion of PSCCF states that the series $\Delta Y_{t}$ have $s$ PSCCFs if a first order polynomial $\delta(L)=\delta_{P}-\delta_{1} L$ exists such that (1) $\delta_{P}^{\prime} \alpha=0$, (2) $\delta_{P}^{\prime} \Gamma_{1}=\delta_{1}$, and (3) $\delta_{P}^{\prime} \Gamma_{i}=0, i=2,3, \ldots, p-1$. The PSCCF restrictions imply that $\delta(L)^{\prime} \psi_{t}=-\delta_{1} C(1) \varepsilon_{t}$. Therefore, the BN cycles of $Y_{t}, \psi_{t}$, have the same PSCCF, if $\Delta Y_{t}$ have the PSCCF structure. In this case, the same PSCCF relationship will cancel the dependence from the past of both $\Delta Y_{t}$ and $\psi_{t}$. 
Two important features of SCCF and PSCCF are: (1) the matrices $\delta_{S}$ and $\delta_{P}$ must lie in the left null space of the loading matrix $\alpha$ containing the adjustment speed coefficients and (2) the long-run dynamics and short-run dynamics are related due to presence of the errorcorrection terms on the right hand side of the VECM model. Hecq et al. (2000, 2002, 2006) introduces a weak form (WF) serial correlation common features notion that relaxes these restrictions.

The WF notion implies the existence of linear combinations of the series $\Delta Y_{t}-\alpha \beta^{\prime} Y_{t-1}$ that are white noise. Under the WF notion of Hecq et al. (2000, 2002, 2006), there exist an $n \times s$ full column matrix $\delta_{W}$ such that $\delta_{W}^{\prime}\left(\Delta Y_{t}-\alpha \beta^{\prime} Y_{t-1}\right)=\delta_{W}^{\prime} \varepsilon_{t}$. In this case, $\Delta Y_{t}$ and $\alpha \beta^{\prime} Y_{t-1}$ have the same serial correlation pattern, their impulse responses are collinear, and they have similar dynamics. This means that the short- and long-run dynamics of $Y_{t}$ are unrelated.

\subsection{Common features test and inference on permanent-transitory shock decomposition}

Testing for cointegration and estimation of cointegration vectors are well established (see, e.g., Johansen, 1996). In this section, we briefly explain the inference in the presence of common features.

Following Johansen (1988, 1991), the maximum likelihood (ML) inference can be based on canonical correlations (CanCor). The likelihood ratio test for the $s$ common feature restrictions is based on the Maximum Likelihood (ML) inference and given in Hecq et al. (2000, 2002, 2006) and Cubadda and Hecq (2001, 2003). The ML inference is equivalent to canonical correlations and can be used to determine the $s$. 
Given that the oil and stock markets might comove both in the short- and long-run, it is of interest to see the relative impacts of transitory and permanent shocks on both variables. The analysis might reveal valuable information on what type of shocks drives these variables in the short- and long-run. The information might also help to disentangle the likely sources of transitory and permanent shocks, some of which are common to each variable.

In a VECM framework, the statistical theory for decomposition of variables in the model into permanent and transitory components (the multivariate $\mathrm{BN}$ decomposition), and IR and FEVD analysis are well established. Our analysis considers both common stochastic trends and common cycles. Therefore, not only the common stochastic trend restrictions but also common cycles restrictions apply in our case.

Our estimation procedure involves the following steps:

1. Decide the number of cointegration vectors $r$ and estimate the VECM (1) with $p-1$ order polynomial $\Gamma(L)$.

2. Fix $\beta$ at estimated values $\hat{\beta}$, determine $s$ and estimate the parameters under common features restrictions.

3. We obtain the estimates of permanent $\left(\hat{u}_{t}^{P}\right)$ and transitory $\left(\hat{u}_{t}^{T}\right)$ shocks and define $\hat{u}_{t}=\left(\hat{u}_{t}^{\prime P}, \hat{u}_{t}^{\prime T}\right)^{\prime}$.

4. Obtain a lover block triangular matrix $\widehat{M}$ using $V=\left[\begin{array}{ll}\alpha_{\perp}^{\prime} & \alpha^{\prime} \Sigma^{-1}\end{array}\right]^{\prime}$, e.g., by applying Choleski decomposition to $\widehat{\Psi}=\operatorname{cov}\left(\widehat{V} \hat{\varepsilon}_{t}\right)=\widehat{M} \widehat{M}^{\prime}$, and construct $\hat{\eta}_{t}=$ $\widehat{M}^{-1} \hat{u}_{t}$. Elements of $\hat{\eta}_{t}$ are mutually uncorrelated and have unit variances.

5. Transform $\hat{C}(L)$ as $\hat{R}(L)=\hat{C}(L) \hat{V}^{-1} \widehat{M}$, which obtains $\Delta Y_{t}=\hat{R}(L) \hat{\eta}_{t}$. 
The IRs, FEVDs, and PT decompositions can then be obtained from the canned routines available in software packages using $\hat{R}(L)$, with the difference that the Choleski decompositions is applied to $\operatorname{cov}\left(\widehat{V} \hat{\varepsilon}_{t}\right)$ rather than to $\operatorname{cov}\left(\hat{\varepsilon}_{t}\right)$.

\section{Data and Results}

We begin our empirical investigation by examining Figure 1 which plots the (log) of S\&P 500 and (log) WTI Crude oil price. Our full sample period extends from September 1859 to July 2015, with the data coming from the Global Financial database. We seasonally adjust the data using the $\mathrm{X}-13$ procedure of the US Census Bureau. We can see that the series move together over time. The spread between the two series increases over time suggesting that the cointegration with a deterministic trend may characterize the series. Along with the tendency of co-movement in the two series, another feature that appears are structural breaks and regime shifts. Short-run changes seem to be harmonized as well.

We turn next to a discussion of descriptive statistics presented in Table 1 which reports metrics for the log level of S\&P 500 and the log WTI oil price as well as log returns of the two series. The average return for the (log) SP500 is 7.8 times higher than the average return for (log) WTI oil price. The WTI return is more volatile than the SP500 return, evidenced by the fact that the coefficient of variation (CV) for WTI returns is 15 times the coefficient of variation (CV) for the SP500 return. Not surprisingly, normality is rejected for both level and return series. Furthermore, returns are negatively skewed, and fat tailed. Both series also exhibit ARCH effects.

Table 2 reports unit root tests, including ADF (Dickey and Fuller, 1981), KPSS (Kwiatkowski et al., 1992), Phillips and Perron (1988), Ng and Perron (2001), DF-GLS 
(Elliott et al., 1996), and Zivot and Andrews (2002) structural break in mean and trend. We conduct these tests over our full sample period, September 1859 to July 2015, as well as the post-WW II sample, October 1945 to July 2015 (owing to a structural break found in 1945 discussed later). All tests indicate uniformly that the (log) level of S\&P 500 and (log) level of WTI oil price are I(1) series for both sample periods.

Table 3 reports Johansen $(1988,1991)$ and Stock and Watson (1988a) cointegration tests. Panel A of Table 3 reports information criteria used to select the lag length in the VAR. We use the AIC criteria and select a lag of 6. The information criteria of BIC and HQ select a lag of 2 . We believe it is preferred to have a longer lag length than a lag length that is too short. Panel B reports the lambda-max and trace statistics when we allow for a deterministic trend in the cointegrating vector. Results indicate evidence of one cointegrating vector (reported in Panel B). The trend in the cointegrating vector is employed as we discussed the visual inspection of the two series in Figure 1. We also conduct cointegration tests without a trend in the cointegrating vector and find evidence of cointegration as well under that specification. Both tests show that log SP500 and log WTI are cointegrated both in the full sample and the post-WW II sample. Panel C reports result for the Stock and Watson (1988a) cointegration tests. The results support the Johansen tests in finding evidence of one cointegrating vector.

We also conducted three parameter constancy test based on the recursive estimation of the vector error correction model (VECM). Recursive estimation is performed over the Jul. 1861Jul. 2015 period with the initial estimation period of Sep. 1859-Jul 1861. The likelihood ratio parameter constancy tests reported in Figure 2 are (a) max test of VECM parameter

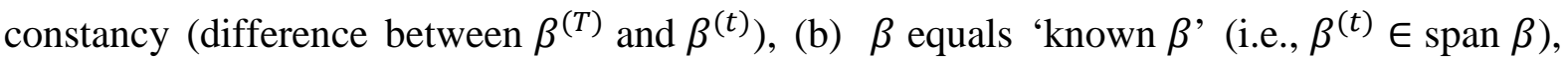
and (c) log-likelihood constancy test. For each tests we report two test types, the $X_{t}$-Form and 
the $R_{t}$-Form. The $X_{t}$-Form tests re-estimates all parameters in the model while the $R_{t}$-Form re-estimates only the long-run parameters. The tests are scaled by the critical value so that the critical value for comparison is 1 . The max parameter constancy test results reported in Figure 2(a) do not reject the parameter constancy, ignoring the initial sample periods for which the recursive estimates might have not converged. The $R_{t}$-Form tests reach a maximum around the WW II period while the $X_{t}$-Form tests reaches a maximum in 1973 . We further check whether the constancy can be supported for $\beta$ equals 'known $\beta$ ', which tests whether $\beta^{(t)} \in \operatorname{span} \beta$. This statistic tests for constancy of the space spanned by $\beta$. The results presented in Figure 2(b) for testing $\beta$ equals 'known $\beta$ ' indicate that the constancy is rejected before 1920 by the $X_{t}$-Form tests and mostly between $1959-1933$ and 1960-1974 periods by the $R_{t}$-Form tests. The log likelihood constancy tests reported in Figure 2(c) indicate that a structural break is most likely to have occurred in 1945. Overall, we obtain some evidence that a structural break most likely to occur around WW II. Figure 2(d) additionally reports the recursive log likelihood estimates scaled by the number of observations in the estimation window. The evidence presented in Figures 2(a)-(d) show that although the particular VECM parameter estimates seem stable, the space spanned by the parameters do not look constant over the sample period, which is evidenced by the log likelihood constancy test. The scaled log likelihood estimates in Figure 2(d) illustrate the possible economic reasons behind the existence of the structural break at the end of WW II. The log likelihood estimates decline significantly beginning at the Great Crash and this decline continues until early 1940s. Then, it starts rising back until 1980s, but it never reaches the level right before 1930. This is probably due to two important forces. First, the Great Crash caused a large decrease in the stock prices, but its effect on the oil prices was milder and come later. Second, in the post-WW II era oil prices had significant government regulation. In the US, the oil prices were regulated for periods Jun. 1947-Jun. 1963 and Apr. 
73-Jun. 1981. The imposition and lift of the oil price controls caused a faster growth for stock prices compared to the oil prices during 1945-1981. There were also significant upward oil price jumps in 1971 and 1978. These events worsened the fit of the model during this period leading to breaks in the long-run and short dynamics.

Because of the structural break around 1945 we also report cointegration tests on a post-WW II sample period, October 1945 to July 2015, in Table 4. For this sample period we employ a lag length of 2 in the VAR and find that both the Johansen and Stock and Watson (1988a) tests indicate evidence of one cointegrating vector. The cointegrating vector for the full sample and the post-WW II period are different reflecting the finding of a structural break. The results for the post-WW II and full sample period differ due to two reasons. First, the long-run parameter estimates across two samples vary up to a sign change, implying a reversal of the impact of oil. The VECM estimates reported in Table 5 show that the impact of stock price on the oil price is 0.6936 in the full sample while it is -1.5095 in the post-WW II sample. Moreover, the trend term in the cointegration relationship also has a sign reversal across the two samples, a change from an insignificant -0.0002 to a highly significant (at $1 \%$ level) 0.0136 . This may be due increased oil dependence and negative impact of oil on the economy due to fast growth after WW II. The second reason is related to the change in the cointegration structure between oil and stock markets. In the pot-WW II period cointegration required a positive significant trend. The existence of a trend in the cointegration specification is similar to a Hicks neutral technological change in a production function. We interpret this unexplained growth effect as arising from the increased GDP growth rate in the post-WW II period, which probably resulted in a faster growth for oil demand particularly enhanced by the end of the oil price regulation in first in Jun. 1957 and second time later in Feb, 1981. Table 5 also show that the adjustment to equilibrium varies significantly in the 
post-WW II sample. The full sample estimates show that the oil prices are weakly endogenously while stock price are weakly exogenous, indicating that it is oil prices do the adjusting back to long-run equilibrium after deviations from the long-run occur. For the postWW II, estimates indicate that both oil and stock prices are weakly endogenous. This result combined with the existence of a significant trend in the cointegration equation in the postWW II period, i.e., the unexplained growth, indicate that both the oil and stock prices are driven by other factors in the post-WW II era, most likely by the stronger GDP growth in this period.

Figure 3 (for the full sample period) plots permanent components of both (log) S\&P500 and (log) WTI oil price as well as the common trend and common cycle series. The upper panel reports the permanent components (in dashed lines) and the actual series (in solid lines). The lower panel shows the common cycle and common trend components of the two series. Figure 4 reports comparable results for the post-WW II period. From the figures we can see that the stock market is driven primarily by the long-run stochastic trend, as actual stock price closely follows the permanent component (see Figures 2(b), 3(b)). The common trend component is mostly driven by the changes in the stock price (see Figures 2(d), 3(d)). It is the oil price that deviates mostly from this long-run common trend. However, this deviation feeds back to the system as the cycle is common during the post-WW II model. So, the deviation of oil price should impact the stock market in the short-run as well. This impact is quite large in the short-run (44\% at step 1 , see Table 8 ). Notice that the post-WW II results in Figure 4 are quite different from the full sample results in Figure 3. For the full sample a common cycle is not found and the permanent shock dominates (see Table 7). Figures 2(b) and 3(b) show that the stock price is always close to its permanent component, while the oil price significantly deviates from its permanent component in several periods. So the common 
cycle is driven by the oil price deviating from the long-run trend. These dynamics might relate to the different dynamics in the oil and stock markets. Oil price had a regulation period as well as major demand boom in the post WW II period. The oil price has grown quite smoothly during 1900-1973 while the stock market was the most volatile during this period. Moreover, the oil price growth was less smoother than the stock market growth before 1900s and after 1973.

Figure 5 reports (for the full sample) impulse response functions for a one standard deviations to a permanent shock for the level of S\&P 500 and the level of oil price (panel a and b) and for S\&P 500 returns and oil returns (panel c and d). Figure 6 reports impulse responses to a transitory shock for the full period. We see a positive and significant response to permanent shocks from both (log) S\&P 500 and (log) oil price. The stock market responds faster and its response is relatively higher than the response of the oil market. For the full sample, the responses of oil and stock price to transitory shocks are asymmetric. Oil responds negatively and significantly, while stock price responds positively but insignificantly. Initial response of oil is very large and negative with some undershooting.

Figure 7 and Figure 8 report comparable results to Figure 5 and Figure 6. In the post-WW II sample, responses to permanent shocks are quite different for the stock market than in the full sample period. The response of oil price in the post-WW II period is negative and significant. The response of oil price in the full sample and post-WW II samples are similar. It is the response of stock market that is largely affected by the structural break. The responses of both oil and stock markets to transitory shocks in the post-WW II sample (Figure 8) vary significantly compared to the full sample model. First, the response of oil price now becomes positive and exponentially decaying as well as the response of the stock market. In the post- 
WW II period we see more changes for oil price's response to transitory shocks. The stock market's response also becomes larger and significant in the post-WWW II sample.

Agents that are interesting in forecasting oil prices over long-periods of time will find these results useful. It has been shown that when variables are cointegrated and there is one common stochastic trend then long-run forecasts can be improved by incorporating the error correction term yield a vector error correction model. Such a model has been shown to have greater forecast accuracy relative to a standard vector error correction model.

Table 6 reports three common cyclical features tests: i) Weak Form (WF) reduced rank structure (Hecq et al. 2000, 2002, 2006); ii) Serial Correlation Common Features (SCCF) (Engle and Kozicki, 1993; Vahid and Engle, 1993), and iii) Polynomial Serial Correlation Common Features (PSCCF) (Cubadda and Hecq, 2001, 2003). Panel A reports the full sample results while Panel B reports post-WW II result. In the full sample, no common cyclical features are found. In the post-WW II sample, WF and SSCF cases indicate a common cyclical feature. AIC, BIC and HQ information criteria all favor the SSCF specification.

Table 7 reports the forecast error variance decomposition for the full sample model for both the oil price and stock price series while the decomposition separates the variance into percentages accounted for by a shock in the common permanent component and a shock in the transitory (cyclical) component. The decomposition is based on the SCCF specification. This table is reported only for comparison purposes only, as we do not find a common cycle in the full sample (see Table 6 discussion). Therefore, the transitory shock should not be assumed as common. In the short-run $98 \%$ of the variance of the oil price is due to transitory 
shocks, declines to $82 \%$ in 60 months. Almost all of the variance (99\% in 1 to 3 months and $100 \%$ afterwards) of the stock price is due to permanent shocks.

Table 8 reports the forecast error variance decomposition for the post-WW II model for the oil price and stock price series. The decomposition splits the variance into percentages accounted for by a shock in the common permanent component and a shock in the common transitory (cyclical) component. The decomposition is based on the SCCF specification. Both the permanent and transitory shocks are common shocks. In the short-run $56 \%$ of the variance of the oil price is due to transitory shocks, this falls to $21 \%$ in 60 months. So, permanent shocks eventually dominate in the long-run and the impact of transitory shocks die off. In the short-run $44 \%$ of the variance of the stock price is due to transitory shocks, this falls to $12 \%$ in 60 months. So, permanent shocks eventually dominate in the long-run and the impact of transitory shocks die off. Transitory shocks account for almost half of the variance for both SP500 and WTI in the short-run, implying that common cyclical fluctuations play a significant role in the short-run but the common permanent shock dominate in the long-run.

\section{Conclusion}

The role played by the stock and oil markets in the US economy is an important area of inquiry. It is important for policy makers to determine what types of shocks drives these two markets. Ascertaining whether shocks are temporary (e.g. aggregate demand shocks) or permanent in nature (aggregate supply shocks), helps in better formulate policy. This paper investigates the role of permanent and transitory shocks, within the framework of common cycles and common trends, in explaining stock and oil prices. This is the first study to determine the nature of shocks that drives these two markets simultaneously. We perform a multivariate variance decomposition analysis of monthly data on the West Texas 
Intermediate (WTI) oil price and the S\&P500. The dataset used in the study spans a long period of 150 years and therefore contains a rich history to examine both the short- and longrun comovement properties of the oil and stock prices. We examine the short- and long-run comovement of oil and stock prices.

This paper centers around two important themes: (a) existence of common stochastic trend (common long-run relation) (b) existence of a common features (i.e. comovement of short run, transitory components). We present decomposition of each series into the independent permanent and transitory components, impulse responses and forecast error variance decompositions in the presence of both common stochastic trends and common cycles. Stock prices and oil prices may commove in the long-run as well as in the short-run.

We employ the Vahid and Engle's (1993) approach to identify common trends and cycles in the context of the multivariate Beveridge and Nelson (1981) decomposition technique. If common-cycle restrictions are correctly imposed, estimates of the dynamic model (a vector autoregression model) are more precise, and leads to more accurate measurement of the relative importance of permanent and transitory shocks. Given that the oil and stock markets might comove both in the short- and long-run, it is of interest to see the relative impacts of transitory and permanent shocks on both variables. The analysis might reveal valuable information on what type of shocks drives these variables in the short- and long-run. The information might also help to disentangle the likely sources of transitory and permanent shocks, some of which are common to each variable. Our analysis considers both the common stochastic trends and common cycles in the bivariate model of oil and stock prices. Therefore, not only the common stochastic trend restrictions but also common cycle restrictions apply in our case. We present decomposition of each series into the independent 
permanent and transitory components, impulse responses, forecast error variance decomposition, in the presence of both common stochastic trends and common cycles. Our analysis reveals that there is a structural break in 1945 in the long-run linkage between log stock price and log oil prices.

For the post WW II period we find that the common trend component is driven primarily by the changes in the stock price. It is the oil price that deviates mostly from this long-run common trend. However, this deviation feeds back to the system as the cycle is common in the post-WW II model. Thus, both the oil and stock prices behave weakly endogenously in the post-WW II model as shown in Table 5. We do not find a common cycle during the postWW II period. The deviation of oil price should impact the stock market in the short-run as well. This impact is quite large in the short-run. The results for the full sample estimates are quite different from the post-WW II results. The results indicate that a common cycle is not found and most things are driven by permanent shocks. We find that the stock price is always close to its permanent component, while the oil price significantly deviates from its permanent component in several periods. So the common cycle is driven by the oil price deviating from the long-run trend. During the post-WW II sample, responses to permanent shocks are quite different for the stock market than in the full sample period. The response of oil price in the post-WW II period is negative and significant. The response of oil price in the full sample and post-WW II samples are similar. It is the response of stock market that is largely affected by the structural break. The responses of both oil and stock markets to transitory shocks in the post-WW II sample vary significantly compared to the full sample model. During the full sample period the response of oil price now becomes positive and exponentially decaying as well as the response of the stock market. In the post-WW II period we see more changes for oil price's response to transitory shocks. The stock market's 
response also becomes larger and significant in the post-WWW II sample. In the post-WW II sample, the WF and SSCF cases indicate a common cyclical feature. AIC, BIC and HQ information criteria all favor the SSCF specification. The forecast error variance decomposition is based on the SCCF specification. For the full sample we find that in the short-run $98 \%$ of the variance of the oil price is due to transitory shocks, declines to $82 \%$ in 60 months. Almost all of the variance (99\% in 1 to 3 months and $100 \%$ afterwards) of the stock price is due to permanent shocks. For the post-WW II period we find both the permanent and transitory shocks are common shocks. In the short-run $56 \%$ of the variance of the oil price is due to transitory shocks, this falls to $21 \%$ in 60 months. Permanent shocks eventually dominate in the long-run and the impact of transitory shocks die out. In the shortrun $44 \%$ of the variance of the stock price is due to transitory shocks, this falls to $12 \%$ in 60 months. Transitory shocks account for almost half of the variance for both (log) SP500 and (log) WTI in the short-run, implying that common cyclical fluctuations play a significant role in the short-run but the common permanent shock dominate in the long-run. The importance of both the permanent and transitory components in explaining the movements in both series (answered by the IRFs and FEVDs) show interestingly that in the short-run oil is driven mostly by cycles (transitory shocks) while the stock market is mostly driven by permanent shocks. But, permanent shocks dominate in the long-run. From the perspective of a policy maker this implies that policy decisions cannot affect the stock market either in short and long-runs, given that it is primarily driven by permanent productivity shocks. However, if there are bubbles in the oil market in the short-run, the policy maker can change interest rates or fiscal decisions to prevent its collapse, and the associated adverse effect on the macroeconomy. In the longer-run, policy decisions cannot affect the oil market just like the stock market. To put it alternatively, changes in policy to correct for possible bubbles in the 
stock market is likely to be a futile exercise, but not so for the oil market, at least in the shortrun. 


\section{References}

Ahamed, L. 2009. Lords of Finance: The Bankers Who Broke the World, New York: Penguin Press.

Angelidis, T., Degiannakis, S. and Filis, G. Forthcoming. US stock market regimes and oil price shocks. Global Finance Journal.

Antonakakis, N. and Filis, G. 2013. Oil prices and stock market correlation: a time-varying approach. International Journal of Energy and Statistics, 1 (1), 17-29.

Antonakakis, N., Chatziantoniou, I., Filis, G. 2014. Dynamic spillovers of oil price shocks and economic policy uncertainty, Energy Economics, 44, 433-447.

Antonakakis, N., Chatziantoniou, I., Filis, G. 2014. Spillovers between oil and stock markets at times of geopolitical unrest and economic turbulence, MRPA Working Paper No. 59760.

Apergis, N., Miller, S. M. 2009. Do structural oil-market shocks affect stock prices?, Energy Economics, 31(4), 569-575.

Balcilar, M., Ozdemir, Z. A. 2013. The causal nexus between oil prices and equity market in the US: A regime switching model, Energy Economics, 39, 271-282.

Balcilar, M., Gupta, R., Miller, S. M. 2015. Regime switching model of US crude oil and stock market prices: 1859 to 2013, Energy Economics, 49, 317-327.

Balke, N. S., Brown, S. P., Yücel, M. K. 2002. Oil price shocks and the US economy: where does the asymmetry originate? The Energy Journal, 27-52.

Balke, N. S., Brown, S., Yucel, M. K. 2010. Oil price shocks and US economic activity: an international perspective, RFF Discussion Paper No. 10-37.

Barro, R. J. 1990. The Stock Market and Investment, Review of Financial Studies, 3(1), 11531.

Barsky, R. B., Kilian, L. 2004. Oil and the Macroeconomy Since the 1970s, The Journal of Economic Perspectives, 18(4), 115-134.

Baumeister, C., Peersman, G. 2013a. The Role of time-varying price elasticities in accounting for volatility changes in the crude oil market, Journal of Applied Econometrics, 28(7), 1087-1109.

Baumeister, C., Peersman, G. 2013b. Time-varying effects of oil supply shocks on the US economy, American Economic Journal: Macroeconomics, 5(4), 1-28.

Baumeister, C., Kilian, L. 2015. 40 years of oil price fluctuations: why the price of oil may still surprise us, Mimeo, University of Notre Dame. 
Beveridge, S., Nelson, C.R., 1981. A new approach to decomposition of economic time series into permanent and transitory components with particular attention to measurement of the business cycle, Journal of Monetary Economics, 7, 151-174.

Bjørnland, H., Larsen, V. H. 2015. Oil and macroeconomic (in) stability. CAMP, Working Paper No. 201507.

Broadstock, D.C. and Filis, G. 2014. Oil price shocks and stock market returns: New evidence from the United States and China. Journal of International Financial Markets, Institutions and Money, 33, 417-433.

Brown, S. P., Yücel, M. K. 2002. Energy prices and aggregate economic activity: an interpretative survey, The Quarterly Review of Economics and Finance, 42(2), 193-208.

Campbell, J. Y., Lettau, M., Malkiel, B. G., Xu Y., 2001. Have Individual Stocks Become More Volatile? An Empirical Eniloration of Idiosynocratic Risk, Journal of Finance, 56, 143.

Chen, N.F., Roll, R., Ross, S., 1986. Economic forces and the stock market. Journal of Business 59, 383-403.

Choi, J. J., Hauser, S., Kopecky, K. J., 1999. Does the Stock Market Predict Real Activity? Time series evidence from the G-7 countries, Journal of Banking \& Finance 23, 1771-1792.

Colombage, S.R.N., 2009. Financial Markets and Economic Performances: Empirical Evidence from Five Industrialized Economies, Research in International Business and Finance, 23, 339-348.

Cubadda, G., Hecq, A. 2001. On Non-Contemporaneous Short- Run Comovements, Economics Letters, 73, 389-397.

Cubadda, G., Hecq, A. 2003. The Role of Common Cyclical Features for Coincident and Leading Indexes Building, Economics \& Statistics Discussion Papers esdp03002, University of Molise, Dept. EGSeI.

Dickey, D., Fuller, W. A. 1981. Likelihood ratio statistics for autoregressive time series with a unit root, Econometrica, 49(4),1057-1072.

Elder, J., Serletis, A. 2010. Oil price uncertainty. journal of money credit and banking, Journal of Money Credit and Banking, 42, 1137-1159.

Elliott, G., Rothenberg, T.J., Stock, J.H., 1996. Efficient tests for an autoregressive unit root, Econometrica, 64, 813-836.

Engle, R.F., Granger, C.W.J., 1987. Cointegration and error correction: representation, estimation and testing, Econometrica, 55, 251-278.

Engle, R.F., Kozicki, S. 1993. Testing for Common Features (with comments), Journal of Business and Economic Statistics, 11, 369-395. 
Engle, R. F., and Issler J.V., (1995). Estimating Common Sectoral Cycles Journal of Monetary Economics 35, 83-113.

Erdogan, O., Bennett, P., Ozyildirim, C. 2015. Recession Prediction Using Yield Curve and Stock Market Liquidity Deviation Measures, Review of Finance, 19(1), 407-422.

Estrella, A., Mishkin, F. S., 1998. Predicting U.S. Recessions: Financial Variables as leading Indicators, Review of Economics and Statistics 80, 45-61.

Fama, E., 1981. Stock Returns, Real Activity, Inflation and Money, American Economic Review, 71, 545-65.

Fama, E. F. 1990. Stock returns, expected returns, and real activity, The Journal of Finance, 45(4), 1089-1108.

Ferguson, N., 2008. The Ascent of Money, New York: Penguin Press.

Fischer, S., Merton, R. C., 1985. Macroeconomics and Finance: The Role of the Stock Market, NBER Working Papers, 1291.

Hamilton, J. D. 1983. Oil and the macroeconomy since World War II, Journal of Political Economy, 91, 228-248.

Hamilton, J. D. 2008. Oil and the macroeconomy. in New Palgrave Dictionary of Economics, $2^{\text {nd }}$ edition, edited by Steven Durlauf and Lawrence Blume, Palgrave McMillan Ltd.

Hamilton, J. D. 2009. Causes and consequences of the oil shock of 2007-08, Brookings Papers on Economic Activity, Spring, 215-259.

Hamilton, J. D. 2011. Historical oil shocks (No. w16790), National Bureau of Economic Research.

Harvey, C. R., 1989. Forecasts of Economic Growth from the Bond and Stock Markets, Financial Analysts Journal, 45, 38-45.

Hecq, A., Palm, F.C., Urbain, J.P. 2000. Permanent-transitory Decomposition in Var Models With Cointegration and Common Cycles, Oxford Bulletin of Economics and Statistics, 62, 511-532.

Hecq, A., Palm, F.C., Urbain, J.P. 2002. Separation, Weak Exogeneity and P-T Decomposition in Cointegrated VAR Systems with Common Features, Econometric Reviews, 21, 273- 307.

Hecq, A., Palm, F.C., Urbain, J.P. 2006. Common cyclical features analysis in VAR models with cointegration, Journal of Econometrics, 132, 117-141.

Hickman, B., Huntington, H., Sweeney, J. 1987, Macroeconomic Impacts of Energy Shocks, North-Holland, Amsterdam. 
Issler, J.V., Vahid, F., 2001. Common cycles and the importance of transitory shocks to macroeconomic aggregates, Journal of Monetary Economics, 47, 449-475.

Issler, J.V., Rodrigues, C.F., and Burjack. R, 2014. Using Common Features to Understand the Behavior of Metal-Commodity Prices and Forecast them at Different Horizons, Journal of International Money and Finance, 42, 310-335.

Johansen, S. 1988. Statistical analysis of cointegration vectors', Journal of Economic Dynamics and Control, 12, 231-54.

Johansen, S. 1991. Estimation and hypothesis of cointegration vectors in Gaussian vector autoregressive models, Econometrica, 59, 1551-81.

Johansen, S., 1996. Likelihood-Based Inference in Cointegrated Vector Autoregressive Models, London: Oxford University Press.

Johansen, S., 2010. Some identification problems in the cointegrated vector autoregressive model, Journal of Econometrics, 158, 262-273.

Jones, C.M., Kaul, G., 1996. Oil and the stock markets. Journal of Finance 51, 463-491.

Jones, D. W., Leiby, P. N., Paik, I. K. 2004. Oil price shocks and the macroeconomy: what has been learned since 1996, The Energy Journal, 1-32.

Kang, W., Ratti, R. A. 2013a. Oil shocks, policy uncertainty and stock market return, International Financial Markets, Institutions and Money, 26, 305-318.

Kang, W., Ratti, R. A. 2013b. Structural oil price shocks and policy uncertainty, Economic Modelling, 35, 314-319.

Kang, W., Ratti, R.A., Yoon, K.H., Forthcoming, Time-Varying Effect of Oil Market Shocks on the Stock Market, Journal of Banking and Finance.

Kilian, L. 2008a. Exogenous oil supply shocks: how big are they and how much do they matter for the US economy?. The Review of Economics and Statistics, 90(2), 216-240.

Kilian, L. 2008b. The Economic Effects of Energy Price Shocks, Journal of Economic Literature, 46(4), 871-909.

Kilian, L. 2009b. Not All Oil Price Shocks Are Alike: Disentangling Demand and Supply Shocks in the Crude Oil Market, American Economic Review, 99(3), 1053-1069.

Kilian, L. 2009b. Comment on 'Causes and Consequences of the Oil Shock of 2007-08'by James D. Hamilton. Brookings Papers on Economic Activity, 1, 267-278.

Kilian, L., Park, C. 2009. The impact of oil price shocks on the us stock market, International Economic Review, 50(4), 1267-1287.

Kilian, L., Vigfusson, R. J. 2011. Nonlinearities in the oil price-output relationship, Macroeconomic Dynamics, 15(S3), 337-363. 
Kilian, L., Vigfusson, R. J. 2013. Do oil prices help forecast us real gdp? the role of nonlinearities and asymmetries, Journal of Business \& Economic Statistics, 31(1), 78-93.

Koopman, S. J., Harvey, A. C., Doornik, J. A., Shephard, N. 2000. STAMP 6.0: Structural Time Series Analyser, Modeller and Predictor, London: Timberlake Consultants.

Kwiatkowski, D., Phillips, P. C., Schmidt, P., Shin, Y. 1992. Testing the null hypothesis of stationarity against the alternative of a unit root: How sure are we that economic time series have a unit root?, Journal of econometrics, 54(1), 159-178.

Mili, M., Sahut, J., Teulon, F., 2012. Nonlinear and asymmetric linkages between real growth in the Euro area and global financial market conditions: New evidence, Economic Modelling 29, 734-741.

Mitchell, W. C., Bums, F., 1938. Statistical Indicators of Cyclical Revivals, NBER Bulletin, 69. Reprinted in: Moore, G.H., (Eds.) Business Cycle Indicators, 1961, Princeton: Princeton U. Press.

Mork, K.A., Hall, R.E., 1980. Energy prices, inflation and recession 1974-75, Energy Journal, 1, 31-63.

Nakov, A. A, Pescatori, A., 2010. Oil and the great moderation, Economic Journal, 120 (543), 131-156.

Narayan, P.K., 2008. Understanding the importance of permanent and transitory shocks at business cycle horizons for the UK, Physica A: Statistical Mechanics and its Applications, 387(12), 2879-2888.

Narayan, P. K. 2011. What drives stock markets over short horizons? Evidence from emerging markets, Quantitative Finance, 11(2), 261-269.

Narayan, P. K., Gupta, R. 2015. Has oil price predicted stock returns for over a century?. Energy Economics, 48, 18-23.

Narayan, P.K., and Narayan, S., 2008a. Do Permanent Shocks Explain Income Levels? A Common Cycle-Common Trend Analysis of Regional Income Levels for China, Pacific Economic Review, 13(5), 656-662.

Narayan, P.K., and Narayan, S., 2008b. The role of permanent and transitory shocks in explaining international health expenditures, Health Economics, 17(10), 1171-1186.

Narayan, P. K., Thuraisamy, K. S. 2013. Common trends and common cycles in stock markets, Economic Modelling, 35, 472-476.

Ng, S., Perron, P. 2001. Lag length selection and the construction of unit root tests with good size and power, Econometrica, 1519-1554. 
Nyberg, H. 2011. Forecasting the direction of the US stock market with dynamic binary probit models, International Journal of Forecasting, 27(2), 561-578.

Perron, P., Ng, S. 1996. Useful modifications to some unit root tests with dependent errors and their local asymptotic properties, The Review of Economic Studies, 63(3), 435-463.

Phillips, P.C.B. 1991. Optimal inference in cointegrated systems, Econometrica, 59, 283306.

Phillips, P. C. B., Perron, P. 1988. Testing for a unit root in time series regression, Biometrika, 75(2):335-346.

Phillips, P.C.B., Yu, J. 2011. Dating the Timeline of Financial Bubbles During the Subprime Crisis, Quantitative Economics, 2, 455-491.

Proietti, T. 1997. Short Run Dynamics in Cointegrated Systems, Oxford Bulletin of Economics and Statistics, 59, 405-422.

Rapach, D. E., Weber, C. E. 2004. Financial Variables and the Simulated Out - of - Sample Forecastability of US Output Growth Since 1985: An Encompassing Approach, Economic Inquiry, 42(4), 717-738.

Rasche, R.H., Tatom, J.A. 1977. The effect of the new energy regime on economic capacity, production and prices, Economic Review, 59, 2-12.

Sadorsky, P., 1999. Oil price shocks and stock market activity. Energy Economics 21, 449469.

Schwert, G. W. 1990. Stock volatility and the crash of'87, Review of financial Studies, 3(1), 77-102.

Stock, J. H., Watson, M. W. (1988a). Variable Trends in Economic Time Series. Journal of Economic Perspectives, vol. 2, no. 3, pp. 147-174.

Stock J., Watson, M. 1988b. Testing for Common Trends, Journal of the American Statistical Association, 83, 1097-1107.

Stock, J. H., Watson, M. W., 1989. New Indexes of Coincident and Leading Economic Indicators, in: Blanchard O.J., Fischer S., (Eds.), NBER Macroeconomics Annual 1989, 35294.

Stock, J. H., Watson, M. W. 2003. Forecasting Output and Inflation: The Role of Asset Prices, Journal of Economic Literature, 41, 788-829.

Vahid F, Engle RF. 1993. Common trends and common cycles. Journal of Applied Econometrics 8: 341-360.

Zivot, E., Andrews, D. W. K. 2002. Further evidence on the great crash, the oil-price shock, and the unit-root hypothesis, Journal of Business and Economic Statistics, 20, 25-44. 
Table 1: Descriptive statistics.

\begin{tabular}{|c|c|c|}
\hline & SP500 & WTI \\
\hline \multicolumn{3}{|c|}{ Panel A: log levels } \\
\hline Mean & 3.381 & 1.435 \\
\hline SD & 1.947 & 1.343 \\
\hline $\mathbf{C V}$ & 0.352 & -2.303 \\
\hline Min & 7.653 & 4.897 \\
\hline Max & 0.732 & 0.707 \\
\hline Skewness & -0.726 & -0.278 \\
\hline Kurtosis & $208.434^{* * *}$ & $162.122^{* * *}$ \\
\hline JB & $1865.708^{* * *}$ & $1860.730^{* * *}$ \\
\hline$Q(1)$ & $7417.626^{* * *}$ & $7320.441^{* * *}$ \\
\hline$Q(4)$ & $1866.888^{* * *}$ & $1841.264^{* * *}$ \\
\hline $\operatorname{ARCH}(1)$ & $1863.956^{* * *}$ & $1844.030^{* * *}$ \\
\hline \multicolumn{3}{|l|}{ ARCH(4) } \\
\hline \multicolumn{3}{|c|}{ Panel B: log returns } \\
\hline Mean & 0.0039 & 0.0005 \\
\hline SD & 0.0476 & 0.0904 \\
\hline $\mathbf{C V}$ & -0.3563 & -0.6931 \\
\hline Min & 0.3524 & 0.7985 \\
\hline Max & -0.5286 & -0.2482 \\
\hline Skewness & 8.6242 & 13.024 \\
\hline Kurtosis & $5899.1800^{* * *}$ & $13270.6490^{* * *}$ \\
\hline JB & $25.1111^{* * *}$ & $277.6604^{* * *}$ \\
\hline$Q(1)$ & $34.0404^{* * *}$ & $324.3194^{* * *}$ \\
\hline$Q(4)$ & $93.6588^{* * *}$ & $201.6846^{* * *}$ \\
\hline $\operatorname{ARCH}(1)$ & $230.4339^{* * *}$ & $299.5312^{* * *}$ \\
\hline ARCH(4) & 0.0039 & 0.0005 \\
\hline$N$ & 1,871 & 1,871 \\
\hline $\begin{array}{l}\text { Th } \\
\text { M } \\
\text { Al } \\
\text { sta } \\
n= \\
\text { of } \\
\text { mi } \\
\text { rep } \\
\text { for } \\
\text { [A } \\
\text { co }\end{array}$ & \multicolumn{2}{|c|}{$\begin{array}{l}\text { The table gives the descriptive statistics for Standard and Poor’s S\&P } 500 \text { Stock } \\
\text { Market Index (SP500), and West Texas Intermediate spot crude oil price (WTI). } \\
\text { All values are in natural logarithms in Panel A. Panel B gives the descriptive } \\
\text { statistics for log returns. The sample period covers Sep. 1859-Jul. } 2015 \text { with } \\
n=1871 \text { observations. S.D. and C.V. denote standard deviation and coefficient } \\
\text { of variation, respectively. In addition to the mean, standard deviation (S.D.), } \\
\text { minimum (min), maximum (max), skewness, and kurtosis statistics, the table } \\
\text { reports the Jarque-Berra normality test (JB), the Ljung-Box first [Q(1)] and the } \\
\text { fourth [Q(4] autocorrelation tests, and the first [ARCH(1)] and the fourth } \\
\text { [ARCH(4)] order Lagrange multiplier (LM) tests for the autoregressive } \\
\text { conditional heteroskedasticity (ARCH). }{ }^{* * *},{ }^{* *} \text { and }{ }^{*} \text { represent significance at the } \\
1 \%, 5 \% \text {, and } 10 \% \text { levels, respectively. }\end{array}$} \\
\hline
\end{tabular}


Table 2: Unit root tests.

\begin{tabular}{|c|c|c|c|c|}
\hline & LnSP500 & LnWTI & LnSP500 & LnWTI \\
\hline & \multicolumn{2}{|c|}{ Full Sample: Sep. 1859 - Jul. 2015} & \multicolumn{2}{|c|}{$\begin{array}{l}\text { Post-WW II Sample: Oct. } 1945 \text { - Jul } \\
2015\end{array}$} \\
\hline \multicolumn{5}{|c|}{ Panel A: Unit-root tests in levels } \\
\hline ADF & $-1.3728[21]$ & $-2.1747[25]$ & $-2.5357[6]$ & $-2.2465[21]$ \\
\hline$Z_{\alpha}$ & $-5.1710[1]$ & $-4.4679[1]$ & $-9.9881[1]$ & $-12.1280[1]$ \\
\hline$M Z_{\alpha}$ & $-5.1669[1]$ & $-4.4660[1]$ & $-9.9389[1]$ & $12.1060[1]$ \\
\hline$M Z_{t}$ & $-1.4641[1]$ & $-2.1236[1]$ & $-2.2289[1]$ & $-2.4485[1]$ \\
\hline DF-GLS & $-1.4620[1]$ & $-1.4326[1]$ & $-2.2335[1]$ & $-2.4313[1]$ \\
\hline KPSS & $0.8678^{* * *}[1]$ & $4.5657^{* * *}[1]$ & $2.7545^{* * *}[1]$ & $1.9687^{* * *}[1]$ \\
\hline Zivot-Andrews & $-5.4187^{* *}[18]$ & $-4.1562[37]$ & $-3.3566[18]$ & $-4.3794[1]$ \\
\hline \multicolumn{5}{|c|}{ Panel B: Unit-root test in first differences } \\
\hline ADF & $-10.1480^{* * *}[19]$ & $-12.8360^{* * *}[23]$ & $-27.6870^{* * *}[0]$ & $-20.353^{* * *}[0]$ \\
\hline$Z_{\alpha}$ & $-512.3800^{* * *}[9]$ & $-2.5211 \mathrm{E}+05^{* * *}[14]$ & $-485.6600^{* * *}[1]$ & $-541.0000^{* * *}[1]$ \\
\hline$M Z_{\alpha}$ & $-43.609^{* * *}[9]$ & $-2.5176 \mathrm{E}+05^{* * *}[14]$ & $-274.3300^{* * *}[1]$ & $-356.6600^{* * *}[1]$ \\
\hline$M Z_{t}$ & $-4.6549^{* * *}[9]$ & $-354.7900^{* * *}[14]$ & $-11.71100^{* * *}[1]$ & $-13.2920^{* * *}[11]$ \\
\hline DF-GLS & $-6.9010^{* * *}[9]$ & $-12.4930^{* * *}[14]$ & $-14.5670^{* * *}[1]$ & $-16.2530^{* * *}[11]$ \\
\hline KPSS & $0.9608[9]$ & $0.0951[14]$ & $0.0515[1]$ & $0.0697[1]$ \\
\hline
\end{tabular}

Note: $\quad$ Panel A reports unit roots tests for the log levels of the series with a constant and a linear trend in the test equation.

Panel B report unit root test for the first differences of the log series with only a constant in the test equation. ADF is the augmented Dickey-Fuller (Dickey and Fuller, 1979) test, $Z_{\alpha}$ is the Phillips-Perron $Z_{\alpha}$ unit root test (Phillips and Perron, 1988), $M Z_{\alpha}$ and $M Z_{t}$ are the modified Phillips-Perron tests of Perron and Ng (1996),

DF-GLS is the augmented Dickey Fuller test of Elliot et al. (1996) with generalized least squares (GLS) detrending, KPSS is theKwiatkowski et al. (1992) stationarity test, and Zivot-Andrews is the endogenous structural break unit root test of Zivot and Andrews (1992) with breaks in both the intercept and linear trend. $Z_{\alpha}, M Z_{\alpha}$, and $M Z_{t}$ tests are based on GLS detrending. For the ADF unit root statistic the lag order is selected by sequentially testing the significance of the last lag at $10 \%$ significance level. The bandwidth or the lag order for the $M Z_{\alpha}, M Z_{t}$, DF-GLS, and KPSS tests are select using the modified Bayesian Information Criterion (BIC)-based data dependent method of Ng and Perron (2001). ${ }^{* * *}$, ${ }^{* *}$ and ${ }^{*}$ represent significance at the $1 \%, 5 \%$, and $10 \%$ levels, respectively. 
Table 3: Multivariate cointegration tests for the full sample: Sep.1859-Jul. 2015.

\section{Panel A: VAR order-selection criteria}

\begin{tabular}{|c|c|c|c|c|c|c|c|}
\hline $\operatorname{ag}(p)$ & 1 & 2 & 3 & 5 & 6 & 7 & 8 \\
\hline IC & -5.2390 & -5.411 & -5.4095 & $-5.4120-5.4109$ & -5.4150 & -5.4129 & -5.4141 \\
\hline & -5.2212 & -5.382 & -5.3679 & $-5.3585-5.3455$ & -5.3377 & -5.3238 & -5.3130 \\
\hline & -5.2324 & -5.401 & -5.3942 & $-5.3922-5.3868$ & -5.3865 & -5.3801 & -5.3768 \\
\hline
\end{tabular}

Panel B: Johansen cointegration tests

Eigenvalues $\quad 0.0175 \quad 0.0019$

\begin{tabular}{ccccccccc} 
& & \multicolumn{3}{c}{ Critical values } & & \multicolumn{3}{c}{ Cointegration vector } \\
\cline { 3 - 4 } \cline { 6 - 8 } Ho & $\lambda_{\text {trace }}$ & $1 \%$ & $5 \%$ & $10 \%$ & & LOIL & LSP & Trend \\
\hline $\boldsymbol{r} \leq \mathbf{1}$ & 3.4905 & 16.5539 & 12.5180 & 10.6664 & & 1.4989 & -1.0396 & 0.0003 \\
$\boldsymbol{r}=\mathbf{0}$ & $36.3757^{* * *}$ & 31.1539 & 25.8721 & 23.3423 & & -0.1685 & 1.4667 & -0.0056
\end{tabular}

\begin{tabular}{cccccccc} 
& & & & & \multicolumn{2}{c}{ Loadings } \\
\cline { 6 - 7 } $\mathbf{H}_{\mathbf{0}}$ & $\lambda_{\max }$ & $1 \%$ & $5 \%$ & $10 \%$ & & LOIL & LSP \\
\cline { 6 - 7 } $\boldsymbol{r}=\mathbf{1}$ & 3.4905 & 16.5539 & 12.5180 & 10.6664 & & -0.0108 & 0.0008 \\
$\boldsymbol{r}=\mathbf{0}$ & $32.8852^{* * *}$ & 23.9753 & 19.3870 & 17.2341 & & -0.0007 & -0.0020
\end{tabular}

Panel C: Stock-Watson cointegration test

\begin{tabular}{|c|c|c|c|}
\hline \multirow{2}{*}{$\begin{array}{c}\mathrm{H}_{0}: q(k, k-r) \\
q(2,0)\end{array}$} & \multirow{2}{*}{$\begin{array}{l}\text { Statistic } \\
-5.1557\end{array}$} & \multicolumn{2}{|c|}{ Critical values for $q(2,1)$} \\
\hline & & $1 \%$ & -38.539 \\
\hline$q(2,1)$ & $-48.6600^{* * *}$ & $5 \%$ & -30.369 \\
\hline & & $10 \%$ & -26.501 \\
\hline
\end{tabular}

Note: $\quad$ Table reports selection criteria and multivariate cointegration tests for the $\operatorname{VAR}(p)$ model of variables LSP, and LOIL. Panel A reports the AIC, BIC, and Hannan-Quinn (HQ) information criteria. The VAR order is selected based on minimum AIC and is 6 . Panel B reports maximal eigenvalue $\left(\lambda_{\max }\right)$ and trace $\left(\lambda_{\text {trace }}\right)$ cointegration order tests of Johansen $(1988,1991)$ with a restricted trend specification. Non-rejection of $r=0$ for the Johansen tests implies no cointegration. Panel C reports the multivariate cointegration test of Stock and Watson (1988a). Under the null $q(k, k-r)$ of Stock-Watson cointegration test, $k$ common stochastic trend is tested against $k-r$ common stochastic trend (or $r$ cointegration relationship). Rejection of $q(2,1)$ for the Stock-Watson test implies cointegration. Numbers in bold are the minimum information criterion values. ${ }^{* * *}$, ${ }^{* *}$ and * represent significance at the $1 \%, 5 \%$, and $10 \%$ levels, respectively. 
Table 4: Multivariate cointegration tests for the post-WW II sample: Oct. 1945-Jul. 2015.

Panel A: VAR order-selection criteria

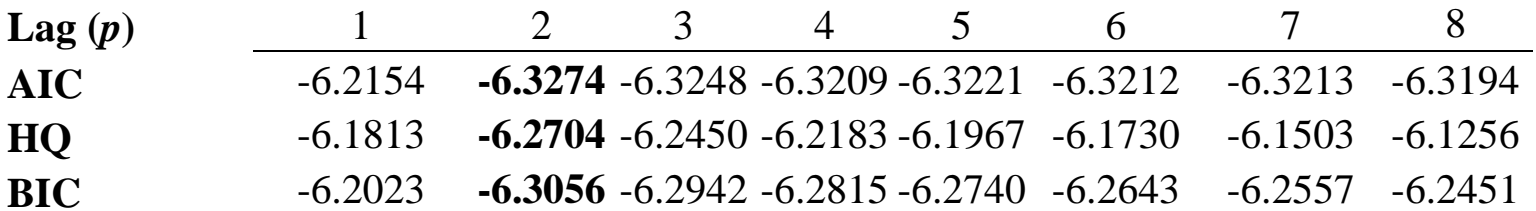

Panel B: Johansen cointegration tests

Eigenvalues $\quad 0.0235 \quad 0.0042$

\begin{tabular}{|c|c|c|c|c|c|c|c|}
\hline \multirow[b]{2}{*}{ Ho } & \multirow[b]{2}{*}{$\lambda_{\text {trace }}$} & \multicolumn{3}{|c|}{ Critical values } & \multicolumn{3}{|c|}{ Cointegration vector } \\
\hline & & $1 \%$ & $5 \%$ & $10 \%$ & LOIL & LSP & Trend \\
\hline$r \leq 1$ & 3.5043 & 16.553 & 2.518 & 10.6664 & -2.8381 & -4.2907 & 0.0386 \\
\hline$r=0$ & $23.3639^{*}$ & 31.153 & 5.872 & 23.3423 & -0.9193 & 2.3233 & -0.0095 \\
\hline
\end{tabular}

\begin{tabular}{|c|c|c|c|c|c|c|}
\hline \multirow[b]{2}{*}{$\mathbf{H}_{\mathbf{0}}$} & \multirow[b]{2}{*}{$\lambda_{\text {max }}$} & \multirow[b]{2}{*}{$1 \%$} & \multirow[b]{2}{*}{$5 \%$} & \multirow[b]{2}{*}{$10 \%$} & \multicolumn{2}{|c|}{ Loadings } \\
\hline & & & & & LOIL & LSP \\
\hline$r=1$ & 3.5043 & 16.553 & 12.51 & 10.6664 & 0.0069 & 0.0042 \\
\hline$r=0$ & $19.8596^{* *}$ & 23.975 & 19.38 & 17.2341 & 0.0024 & -0.0021 \\
\hline
\end{tabular}

Panel C: Stock-Watson cointegration test

\begin{tabular}{|c|c|c|}
\hline $\mathrm{H}_{0}: q(k, k-r)$ & Statistic & Critical values for $q(2,1)$ \\
\hline$q(2,0)$ & -7.2332 & -38.539 \\
\hline$q(2,1)$ & $-39.263^{* * *}$ & $\begin{array}{l}-30.369 \\
-26501\end{array}$ \\
\hline
\end{tabular}

Note: $\quad$ Table reports selection criteria and multivariate cointegration tests for the VAR(p) model of variables LSP, and LOIL. Panel A reports the AIC, BIC, and Hannan-Quinn (HQ) information criteria. The VAR order is selected as 2 by all information criteria. Panel B reports maximal eigenvalue $\left(\lambda_{\max }\right)$ and trace $\left(\lambda_{\text {trace }}\right)$ cointegration order tests of Johansen $(1988,1991)$ with a restricted trend specification. Non-rejection of $r=0$ for the Johansen tests implies no cointegration. Panel C reports the multivariate cointegration test of Stock and Watson (1988a). Under the null $q(k, k-r)$ of Stock-Watson cointegration test, $k$ common stochastic trend is tested against $k-r$ common stochastic trend (or $r$ cointegration relationship). Rejection of $q(2,1)$ for the Stock-Watson test implies cointegration. Numbers in bold are the minimum information criterion values. ${ }^{* * *}$, ${ }^{* *}$ and * represent significance at the $1 \%, 5 \%$, and $10 \%$ levels, respectively. 
Table 5: Estimates of the vector error correction models.

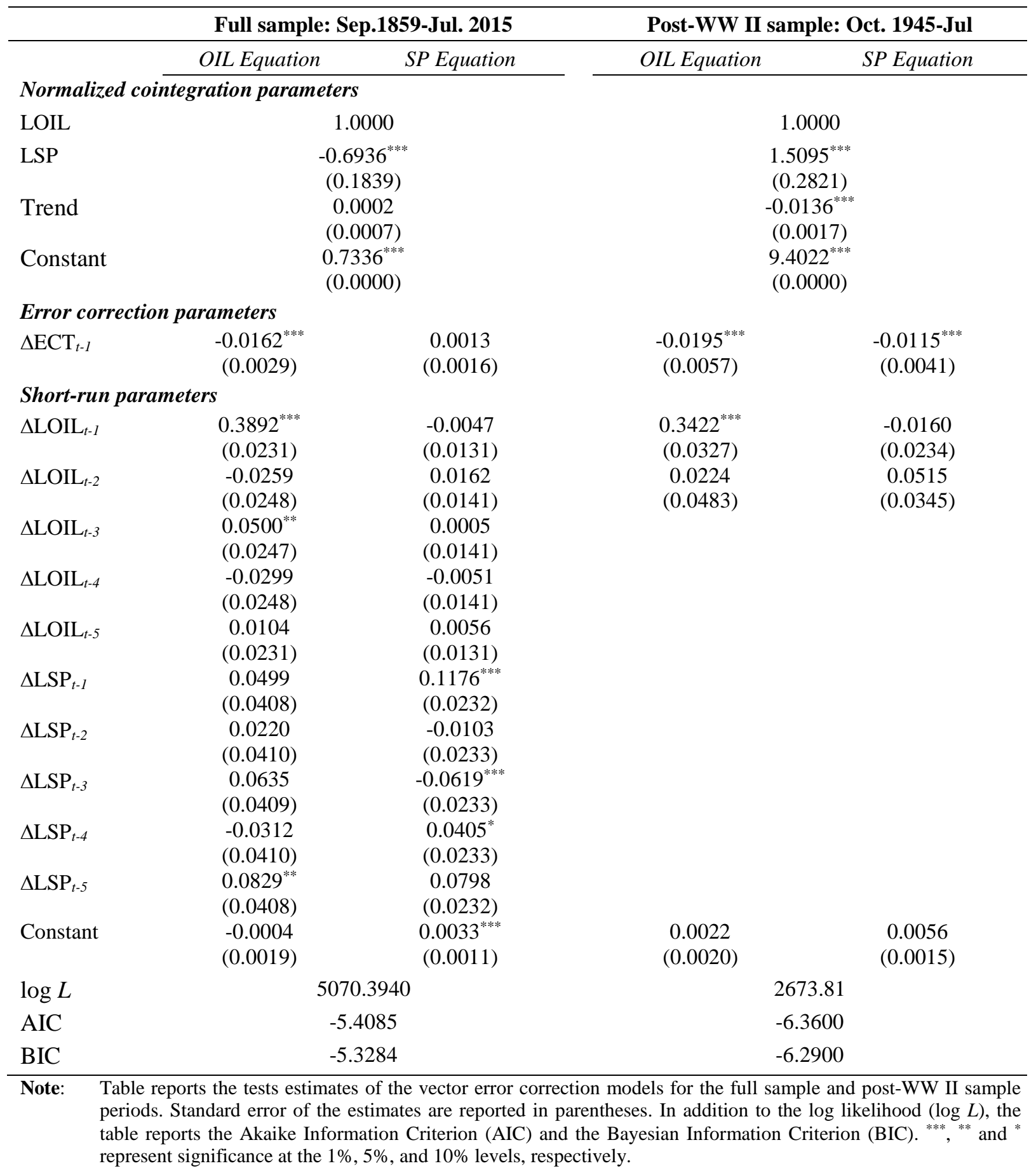


Table 6: Common cyclical features tests using reduced rank regression.

Panel A: Full Sample, Sep. 1859 - Jul. 2015

\begin{tabular}{lcccccccc} 
Model & $\boldsymbol{H}_{\mathbf{0}}$ & $\hat{\lambda}$ & $\chi^{2}$ & $\log L$ & $p$-value & AIC & HQ & BIC \\
\hline (i) WF & & & & & & & & \\
& $s \geq 1$ & 0.0269 & $50.8264^{* * *}$ & 10337.60 & $>0.0001$ & -11.072 & -11.058 & -11.033 \\
& $s \geq 2$ & 0.1579 & $371.3850^{* * *}$ & 10177.30 & $>0.0001$ & -10.912 & -10.910 & -10.906
\end{tabular}

(ii) SCCF

$\begin{array}{llllllll}s \geq 1 & 0.0273 & 51.7097^{* * *} & 10337.20 & >0.0001 & -11.073 & -11.059 & -11.037 \\ s \geq 2 & 0.1695 & 398.0150^{* * *} & 10164.00 & >0.0001 & -10.900 & -10.900 & -10.900\end{array}$

(iii) PSCCF

$\begin{array}{llllclll}s \geq 1 & 0.0134 & 25.1295^{* * *} & 10350.50 & 0.0015 & \mathbf{- 1 1 . 0 8 5} & \mathbf{- 1 1 . 0 6 9} & \mathbf{- 1 1 . 0 4 3} \\ s \geq 2 & 0.0242 & 70.8467^{* * *} & 10327.60 & >0.0001 & -11.071 & -11.067 & -11.059\end{array}$

Panel B: Post-WW II Sample, Oct. 1945 - Jul. 2015

\begin{tabular}{|c|c|c|c|c|c|c|c|c|}
\hline Model & $\mathrm{H}_{0}$ & $\hat{\lambda}$ & $\chi^{2}$ & $\log L$ & $p$-value & AIC & HQ & BIC \\
\hline \multicolumn{9}{|l|}{ (i) $\mathrm{WF}$} \\
\hline & $s \geq 1$ & 0.0027 & 2.2253 & 5037.30 & 0.1358 & -11.922 & -11.918 & -11.911 \\
\hline & $s \geq 2$ & 0.1164 & $105.7250^{* * *}$ & 4985.55 & $>0.0001$ & -12.039 & -12.028 & -12.011 \\
\hline \multicolumn{9}{|c|}{ (ii) SCCF } \\
\hline & $s \geq 1$ & 0.0071 & $5.9435^{*}$ & 5037.67 & 0.0512 & -12.042 & -12.034 & -12.020 \\
\hline & $s \geq 2$ & 0.1304 & $122.7210^{* * *}$ & 4979.28 & $>0.0001$ & -11.912 & -11.912 & -11.912 \\
\hline
\end{tabular}

(iii) PSCCF

$\begin{array}{cccccccc}s \geq 1 & 0.0033 & 2.7955 & 5034.29 & 0.2472 & -12.039 & -12.022 & -11.994 \\ s \geq 2 & 0.0302 & 28.4194^{* * *} & 5021.47 & 0.0001 & -12.018 & -12.009 & -11.995\end{array}$

Note: $\quad$ Table reports the tests for $s$ common cyclical features for three types of models (restrictions): (i) Weak Form (WF) reduced rank structure (Hecq et al. 2000, 2002, 2006), (ii) Serial Correlation Common Features (SCCF) (Engle and Kozicki, 1993; Vahid and Engle, 1993), and (iii) Polynomial Serial Correlation Common Features (PSCCF) (Cubadda and Hecq, 2001, 2003). All there restrictions lead to likelihood ratio tests, which distributed as $\chi^{2}$ with degrees of freedom equal to number of restrictions. In the table $\hat{\lambda}$ are the eigenvalues form canonical correlation problems relating to the three types of restrictions, $\log L$ is the $\log$ likelihood of the model under the specification, and $p$-value is for the $\chi^{2}$ test given in the fourth column. AIC, BIC, and HQ are the Akaika, Bayesian, and HannanQuinn information criterion, respectively. Numbers in bold are the minimum information criterion values. ${ }^{* * *},{ }^{* *}$ and * represent significance at the $1 \%, 5 \%$, and $10 \%$ levels, respectively, and ">" means "less than" the following it. 
Table 7: Forecast Error Variance Decomposition for the full sample common features model: Sep. 1859-Jul. 2015.

\begin{tabular}{|c|c|c|c|c|}
\hline & \multicolumn{2}{|c|}{ Variance Decomposition of LOIL } & \multicolumn{2}{|c|}{ Variance Decomposition of LSF } \\
\hline \multicolumn{5}{|c|}{ Variance due to: } \\
\hline Step & $\begin{array}{c}\text { Permanent } \\
\text { shock }\end{array}$ & $\begin{array}{c}\text { Transitory } \\
\text { shock }\end{array}$ & $\begin{array}{c}\text { Permanent } \\
\text { shock }\end{array}$ & $\begin{array}{c}\text { Transitory } \\
\text { shock }\end{array}$ \\
\hline 1 & 0.02 & 0.98 & 0.99 & 0.01 \\
\hline 2 & 0.02 & 0.98 & 0.99 & 0.01 \\
\hline 3 & 0.03 & 0.97 & 0.99 & 0.01 \\
\hline 4 & 0.03 & 0.97 & 1.00 & 0.00 \\
\hline 5 & 0.04 & 0.96 & 1.00 & 0.00 \\
\hline 6 & 0.04 & 0.96 & 1.00 & 0.00 \\
\hline 7 & 0.05 & 0.95 & 1.00 & 0.00 \\
\hline 8 & 0.05 & 0.95 & 1.00 & 0.00 \\
\hline 9 & 0.05 & 0.95 & 1.00 & 0.00 \\
\hline 10 & 0.06 & 0.94 & 1.00 & 0.00 \\
\hline 11 & 0.06 & 0.94 & 1.00 & 0.00 \\
\hline 12 & 0.06 & 0.94 & 1.00 & 0.00 \\
\hline 13 & 0.06 & 0.94 & 1.00 & 0.00 \\
\hline 14 & 0.07 & 0.93 & 1.00 & 0.00 \\
\hline 15 & 0.07 & 0.93 & 1.00 & 0.00 \\
\hline 16 & 0.07 & 0.93 & 1.00 & 0.00 \\
\hline 17 & 0.07 & 0.93 & 1.00 & 0.00 \\
\hline 18 & 0.08 & 0.92 & 1.00 & 0.00 \\
\hline 19 & 0.08 & 0.92 & 1.00 & 0.00 \\
\hline 20 & 0.08 & 0.92 & 1.00 & 0.00 \\
\hline 30 & 0.10 & 0.90 & 1.00 & 0.00 \\
\hline 40 & 0.13 & 0.87 & 1.00 & 0.00 \\
\hline 50 & 0.15 & 0.85 & 1.00 & 0.00 \\
\hline 60 & 0.18 & 0.82 & 1.00 & 0.00 \\
\hline
\end{tabular}


Table 8: Forecast Error Variance Decomposition for the post-WW II common features model: Oct. 1945-Jul. 2015.

\begin{tabular}{|c|c|c|c|c|}
\hline & \multicolumn{2}{|c|}{ Variance Decomposition of LOIL } & \multicolumn{2}{|c|}{ Variance Decomposition of LSP } \\
\hline \multicolumn{5}{|c|}{ Variance due to: } \\
\hline Step & $\begin{array}{l}\text { Permanent } \\
\text { shock }\end{array}$ & $\begin{array}{c}\text { Transitory } \\
\text { shock }\end{array}$ & $\begin{array}{c}\text { Permanent } \\
\text { shock }\end{array}$ & $\begin{array}{c}\text { Transitory } \\
\text { shock }\end{array}$ \\
\hline 1 & 0.44 & 0.56 & 0.56 & 0.44 \\
\hline 2 & 0.45 & 0.55 & 0.59 & 0.41 \\
\hline 3 & 0.46 & 0.54 & 0.59 & 0.41 \\
\hline 4 & 0.47 & 0.53 & 0.59 & 0.41 \\
\hline 5 & 0.48 & 0.52 & 0.59 & 0.41 \\
\hline 6 & 0.49 & 0.51 & 0.60 & 0.40 \\
\hline 7 & 0.50 & 0.50 & 0.60 & 0.40 \\
\hline 8 & 0.51 & 0.49 & 0.61 & 0.39 \\
\hline 9 & 0.52 & 0.48 & 0.62 & 0.38 \\
\hline 10 & 0.53 & 0.47 & 0.63 & 0.37 \\
\hline 11 & 0.54 & 0.46 & 0.64 & 0.36 \\
\hline 12 & 0.54 & 0.46 & 0.65 & 0.35 \\
\hline 13 & 0.55 & 0.45 & 0.66 & 0.34 \\
\hline 14 & 0.56 & 0.44 & 0.67 & 0.33 \\
\hline 15 & 0.57 & 0.43 & 0.68 & 0.32 \\
\hline 16 & 0.58 & 0.42 & 0.69 & 0.31 \\
\hline 17 & 0.59 & 0.41 & 0.69 & 0.31 \\
\hline 18 & 0.60 & 0.40 & 0.70 & 0.30 \\
\hline 19 & 0.60 & 0.40 & 0.71 & 0.29 \\
\hline 20 & 0.61 & 0.39 & 0.72 & 0.28 \\
\hline 30 & 0.68 & 0.32 & 0.78 & 0.22 \\
\hline 40 & 0.73 & 0.27 & 0.83 & 0.17 \\
\hline 50 & 0.76 & 0.24 & 0.86 & 0.14 \\
\hline 60 & 0.79 & 0.21 & 0.88 & 0.12 \\
\hline
\end{tabular}


Figure 1: Natural Logarithms of SP500 and WTI: Sept.1859-Jul. 2015

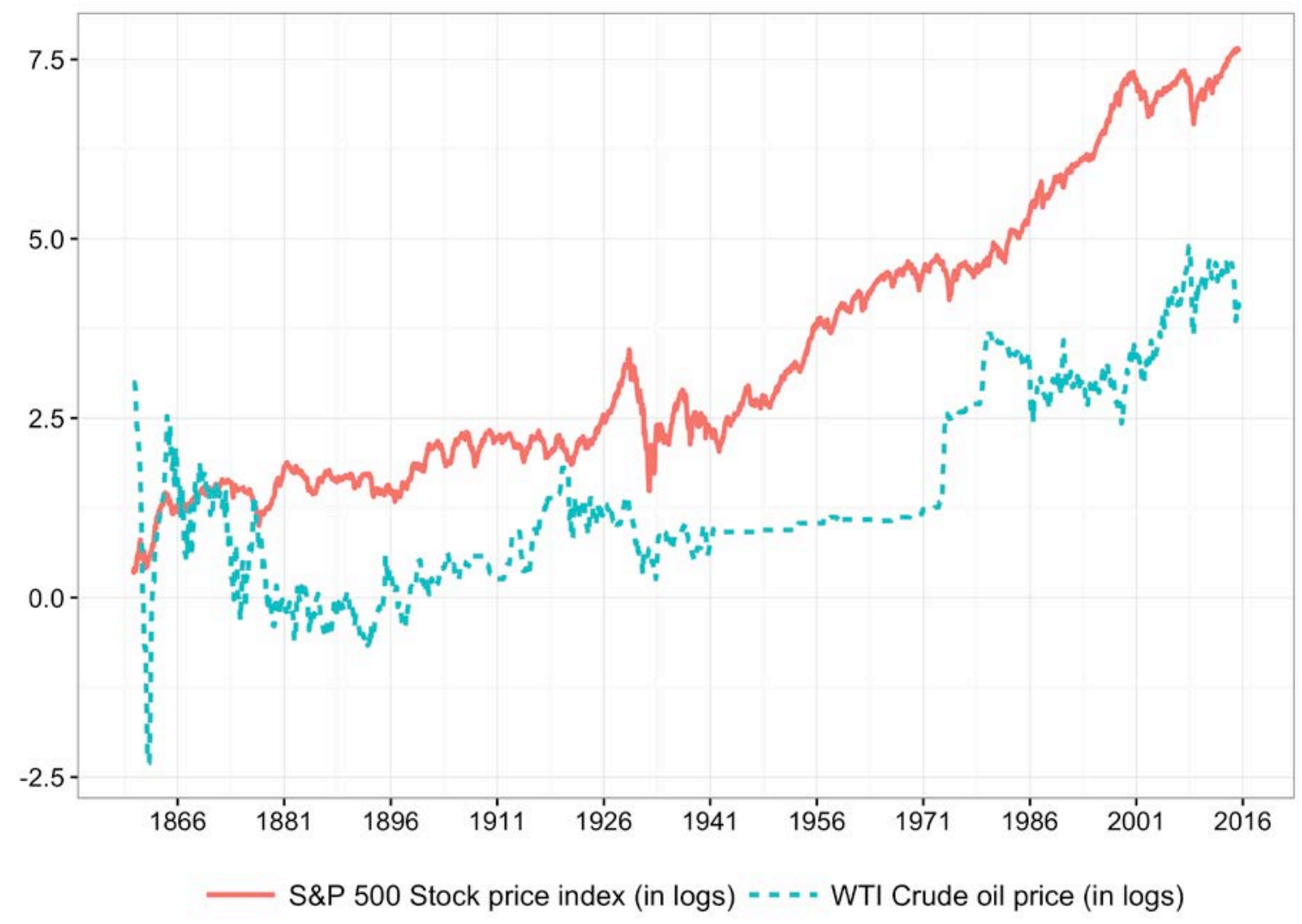




\section{Figure 2: Constancy tests for the log likelihood of the VECM model}

(a) Max test of $\beta$ constancy tests

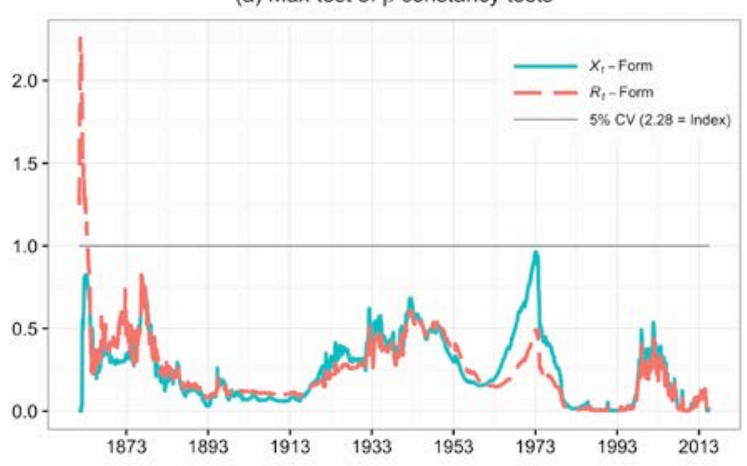

(b) Test of $\beta=$ 'known $\beta$ '



(c) Log-likelihood constancy test

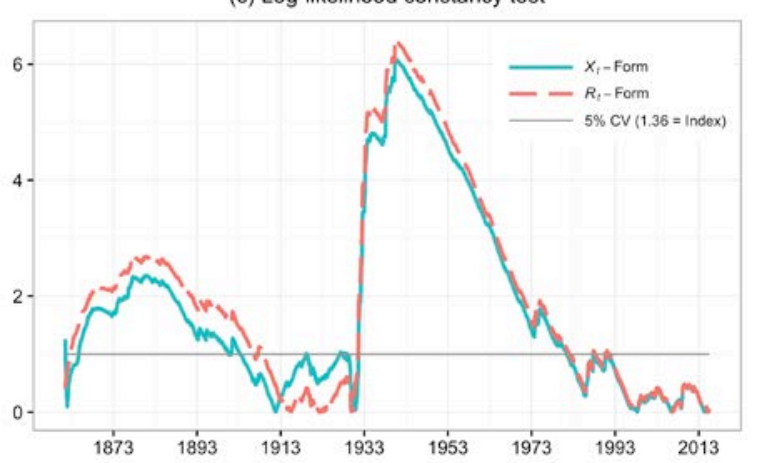

(d) Recursive log lokelihood

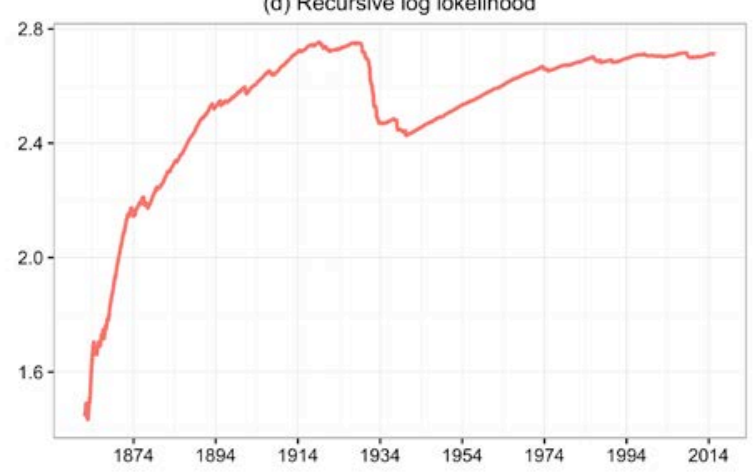

Note: Figure reports recursive constancy tests for (a) VECM parameters (difference between $\beta^{(T)}$ and $\beta^{(t)}$ ), (b) $\beta$ equals 'known $\beta^{\prime}$ ( $\left.\beta^{(t)} \in \operatorname{span} \beta\right)$, (c) log-likelihood. The $X_{t}$-Form tests re-estimates all parameters in the model while the $R_{t}$-form re-estimates only the long-run parameters. The tests are scaled by the critical value so that the critical for comparison is 1 . Part (d) of the figure additionally reports the recursive log likelihood estimates scaled by the number of observations in the estimation window. Recursive estimation is performed over the Jul. 1861-Jul.2015 period with the initial estimation period Sep. 1859-Jul 1861 (23 observations). 
Figure 3: Estimates of the common features for the full sample: Sep. 1859-Jul. 2015.

(a) Permanent component of LOIL



(c) Common cycle

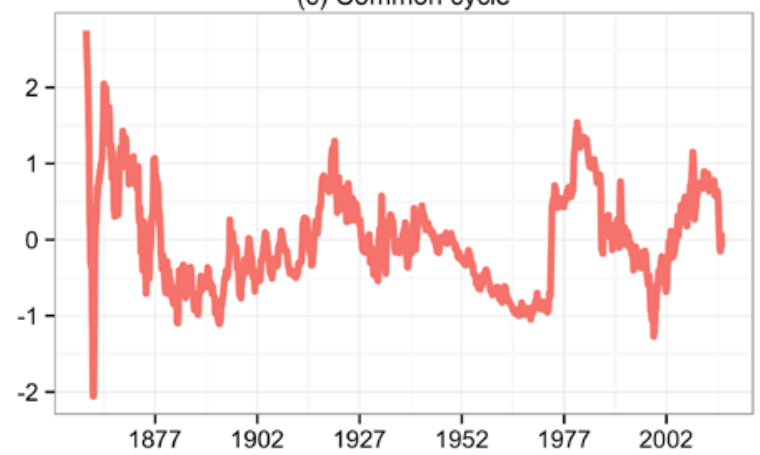

(b) Permanent component of LSP

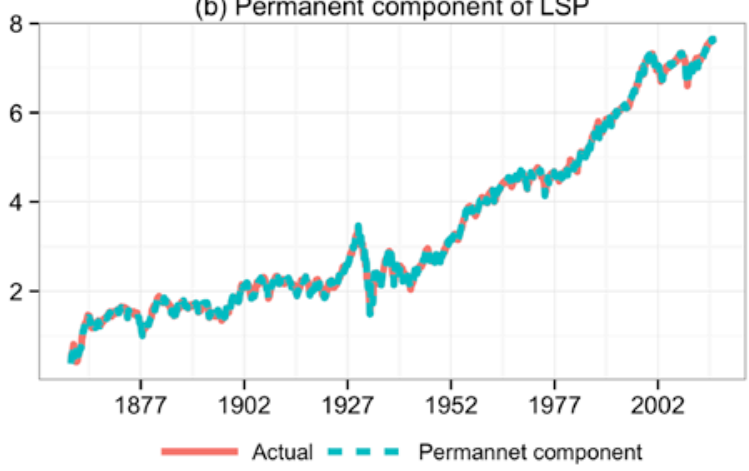

(d) Common trend

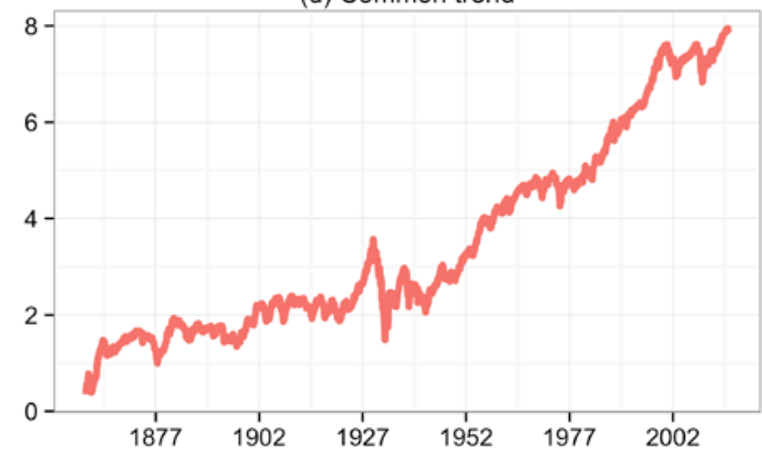

Note: The decomposition is based on the SSCF model, which selected jointly by all information criteria. 
Figure 4: Estimates of the common features for the post-WW II sample: Oct. 1945-Jul. 2015.

(a) Permanent component of LOIL

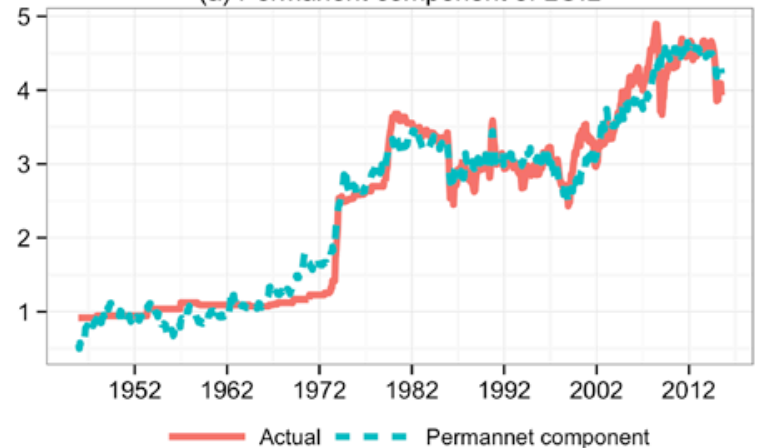

(c) Common cycle

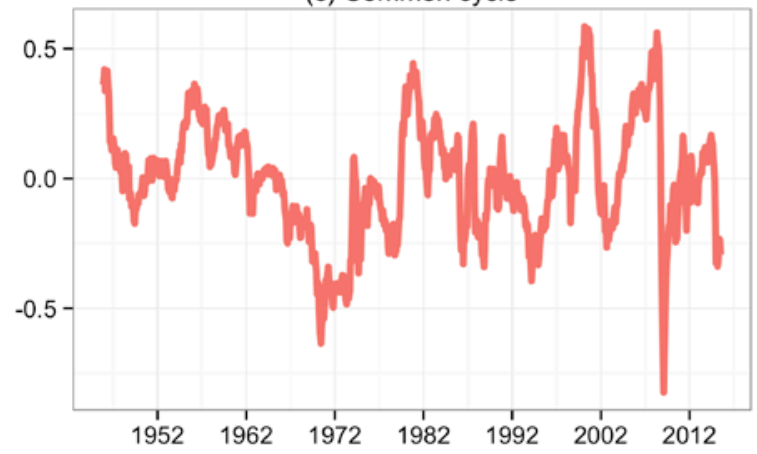

(b) Permanent component of LSP

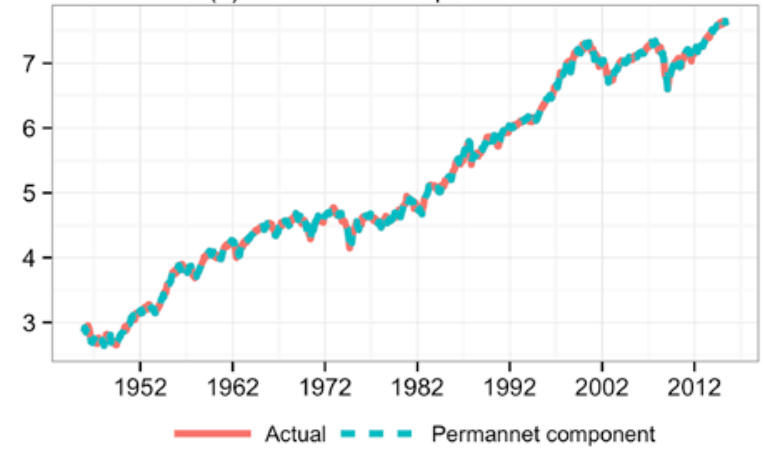

(d) Common trend

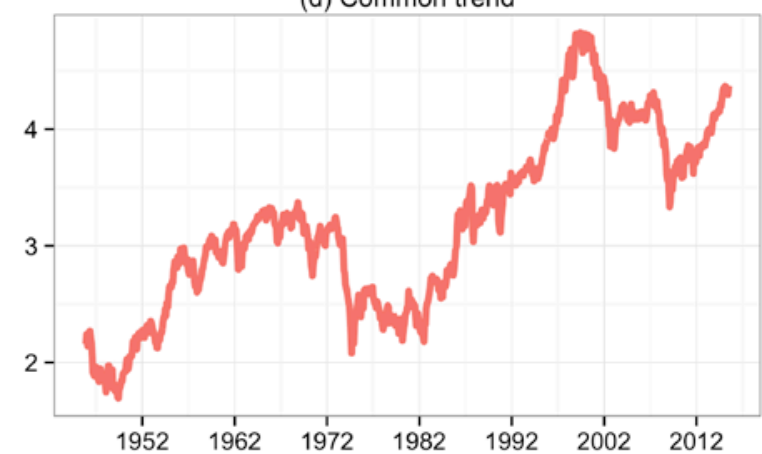

Note: The decomposition is based on the SSCF model, which selected jointly by all information criteria. 
Figure 5: Impulse responses to a permanent shock for the full sample: Sep. 1859-Jul. 2015.

(a) Response of LOIL to 1 s.d. permanent shock

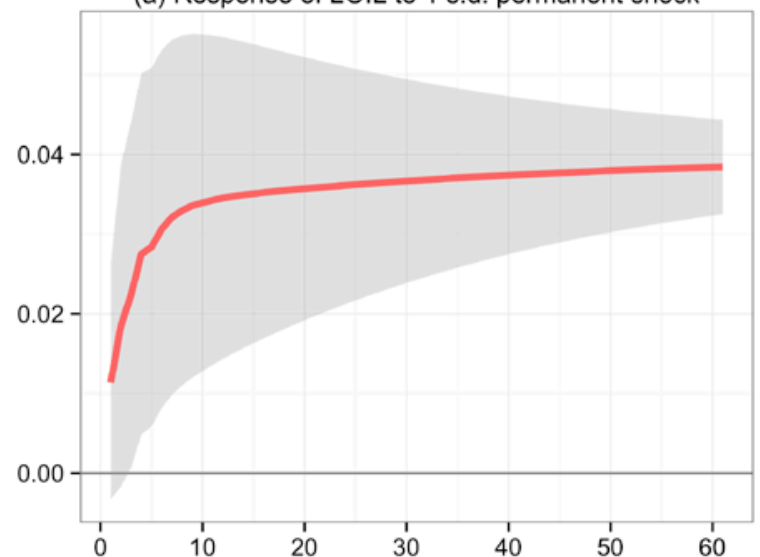

(c) Response of $\Delta$ LOIL to 1 s.d. permanent shock

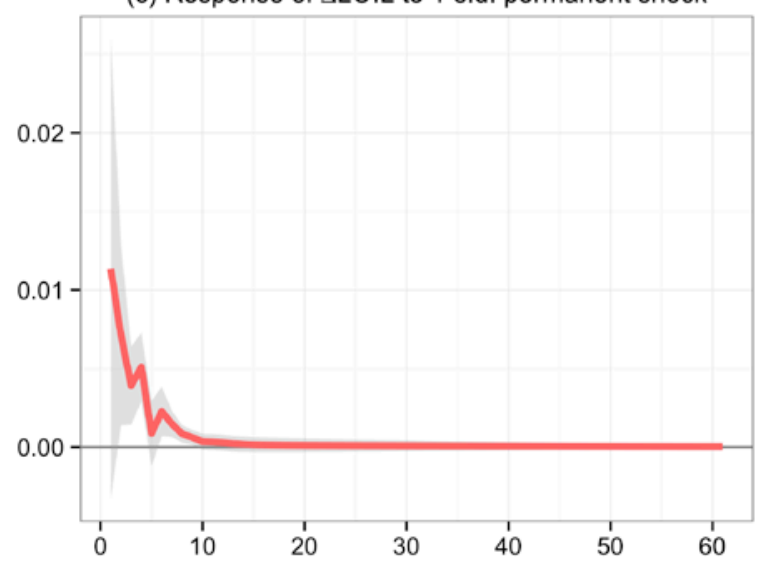

(b) Response of LSP to 1 s.d. permanent shock

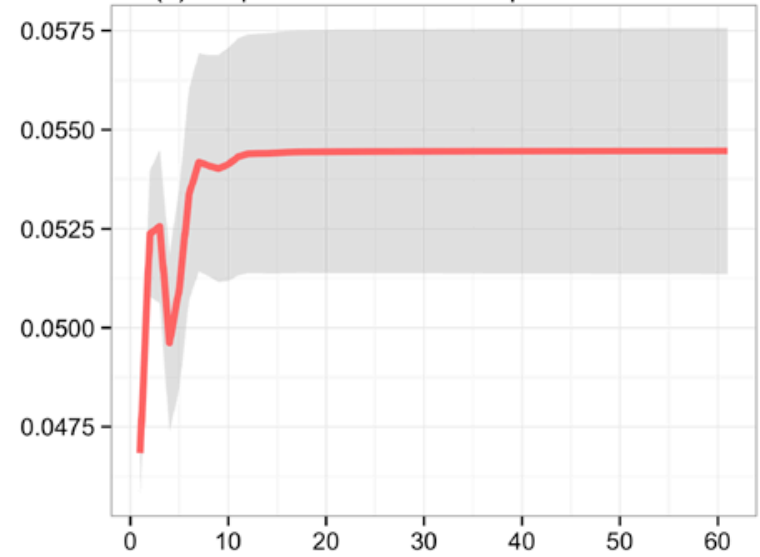

(d) Response of $\Delta$ LSP to 1 s.d. permanent shock

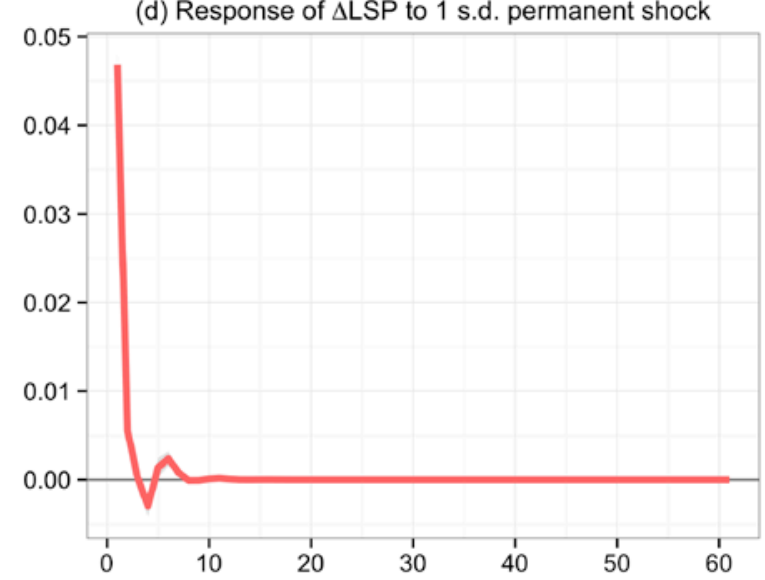

Note: The figure gives the impulse responses to a 1 standard deviation shock in the permanent component. The impulse responses are obtained the SSCF model, which selected jointly by all information criteria. The horizontal axis represents the steps in months. The solid line denotes the impulse response, while shaded region around the impulse response line represent the $68 \%$ ( \pm 1 standard deviation) confidence interval. 
Figure 6: Impulse responses to a transitory shock for the full sample: Sep. 1859-Jul. 2015.

(a) Response of LOIL to 1 s.d. transitory shock

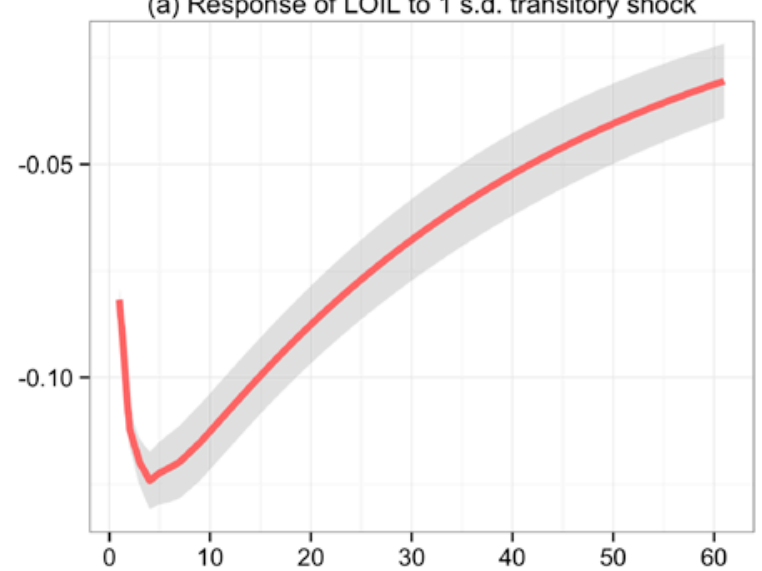

(c) Response of $\Delta$ LOIL to 1 s.d. transitory shock

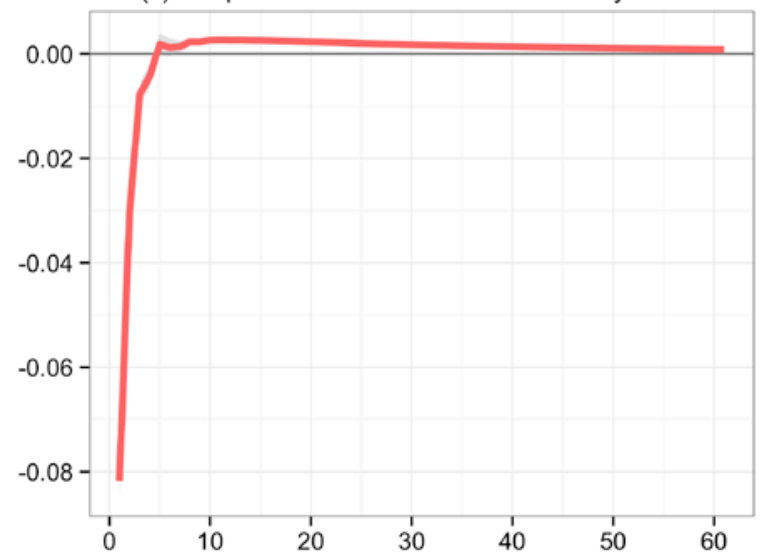

(b) Response of LSP to 1 s.d. transitory shock

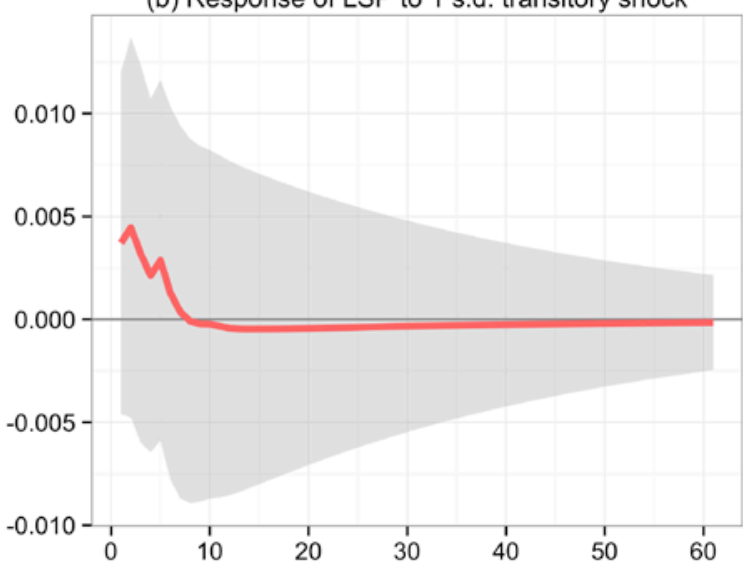

(d) Response of $\Delta \mathrm{LSP}$ to 1 s.d. transitory shock

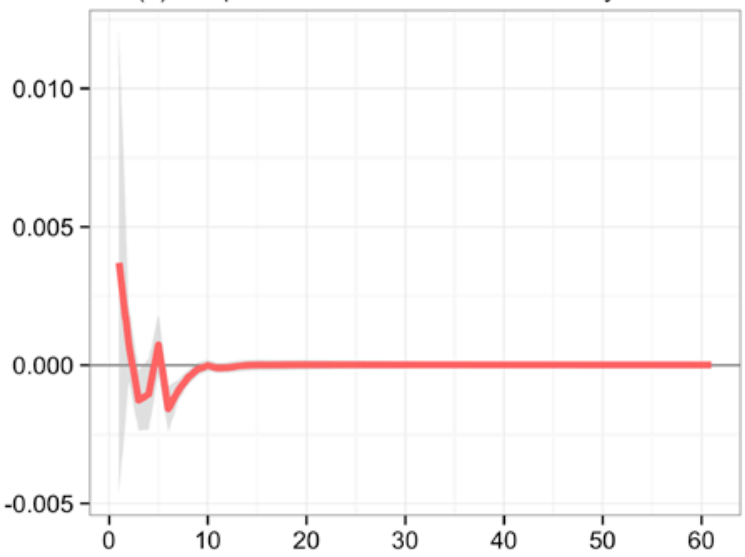

Note: The figure gives the impulse responses to a 1 standard deviation shock in the transitory component. The impulse responses are obtained the SSCF model, which selected jointly by all information criteria. The horizontal axis represents the steps in months. The solid line denotes the impulse response, while shaded region around the impulse response line represent the $68 \%$ ( \pm 1 standard deviation) confidence interval. 
Figure 7: Impulse responses to a permanent shock for the post-WW II: Oct. 1945-Jul. 2015.

(a) Response of LOIL to 1 s.d. permanent shock

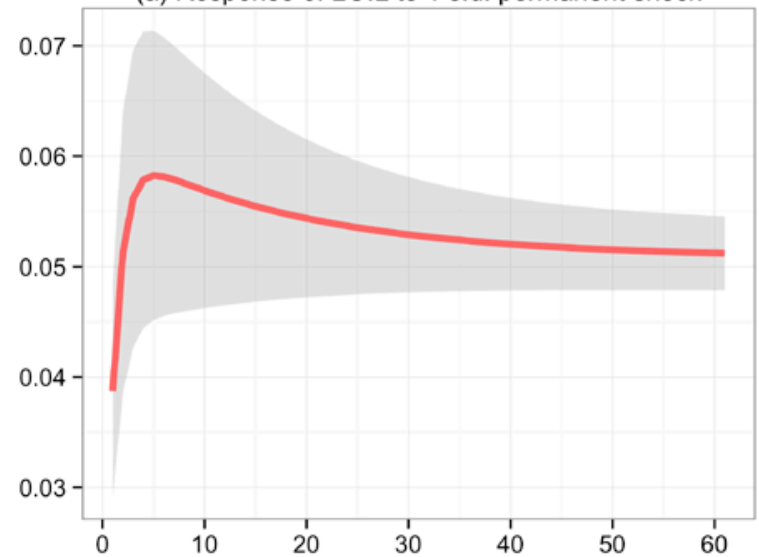

(c) Response of $\Delta$ LOIL to 1 s.d. permanent shock

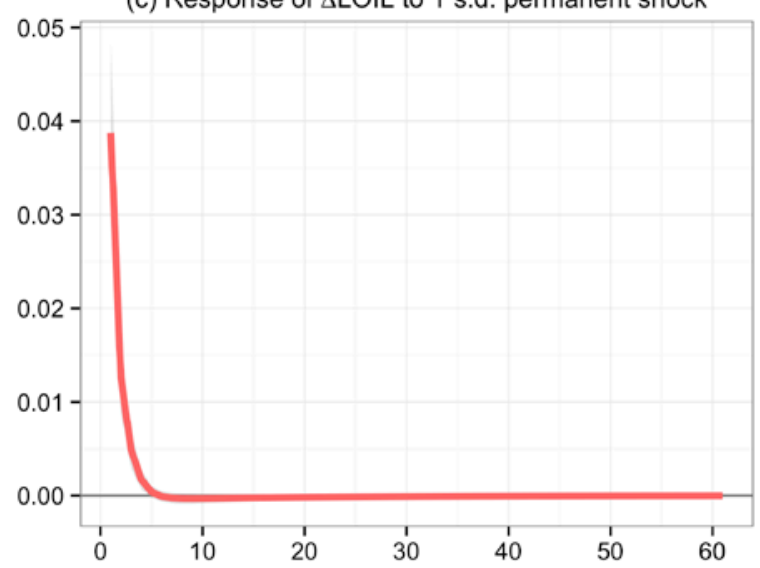

Note: See Note to Figure 5. (b) Response of LSP to 1 s.d. permanent shock

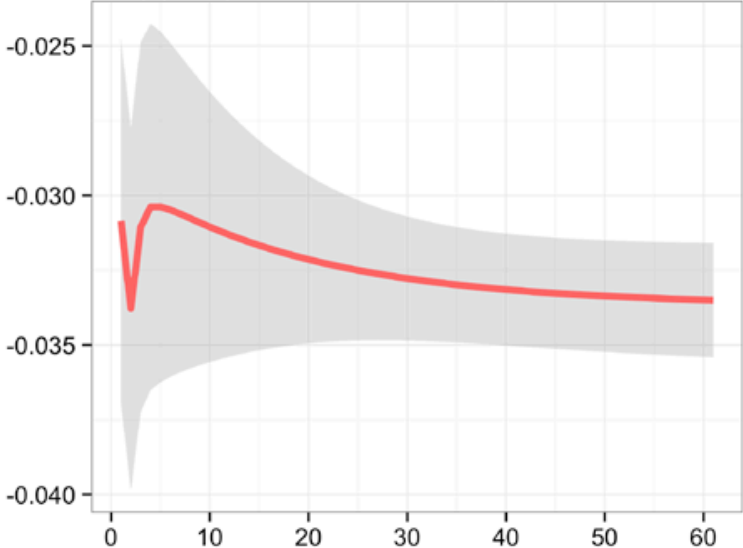

(d) Response of $\Delta$ LSP to 1 s.d. permanent shock

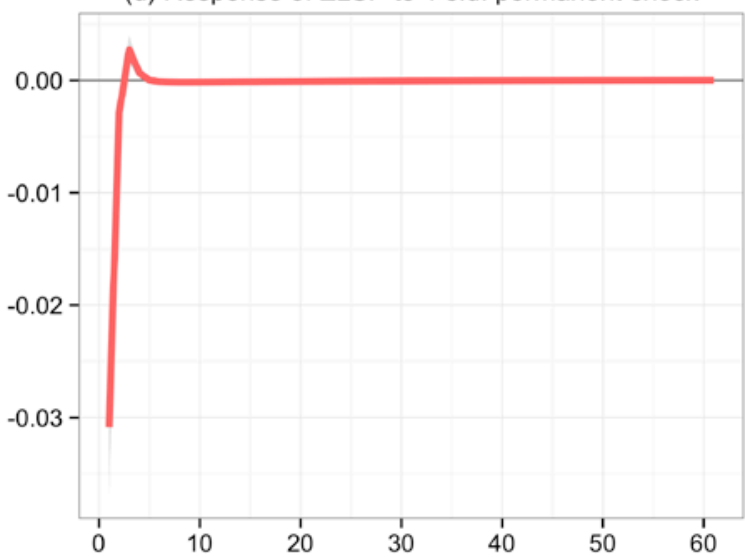


Figure 8: Impulse responses to a transitory shock for the post-WW II: Oct. 1945-Jul. 2015.
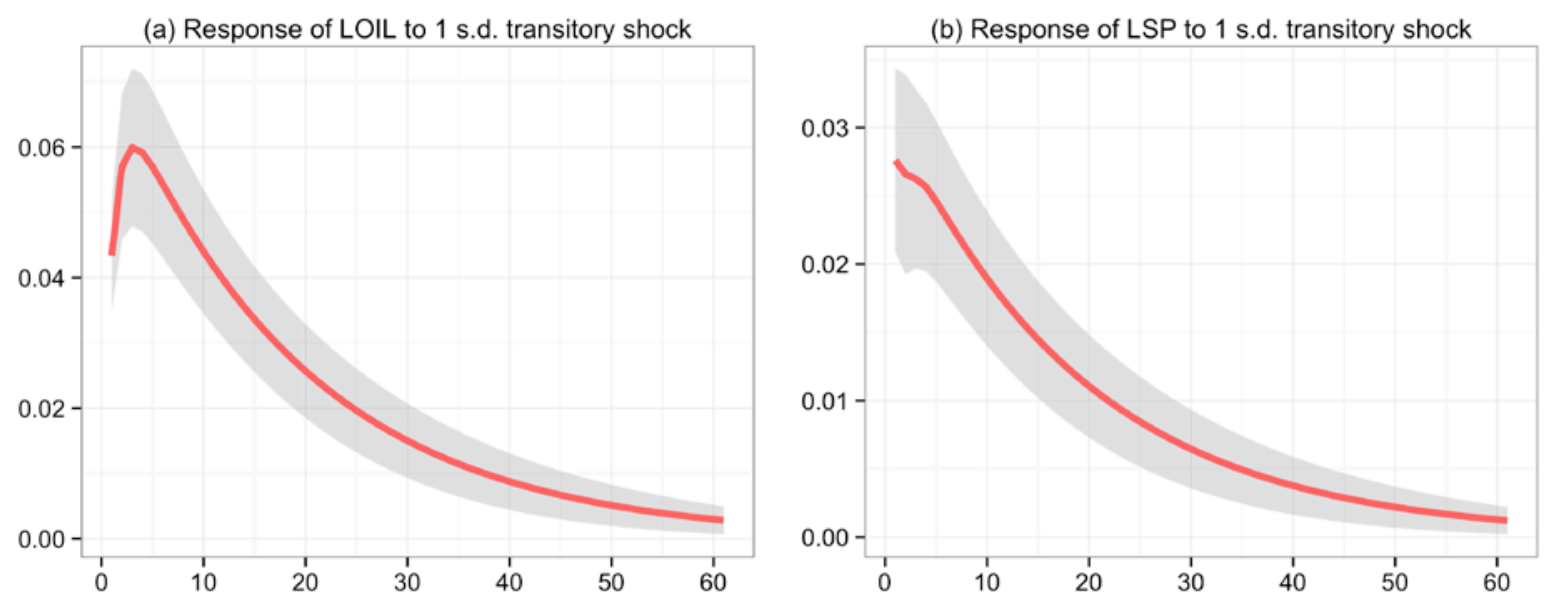

(c) Response of $\Delta$ LOIL to 1 s.d. transitory shock

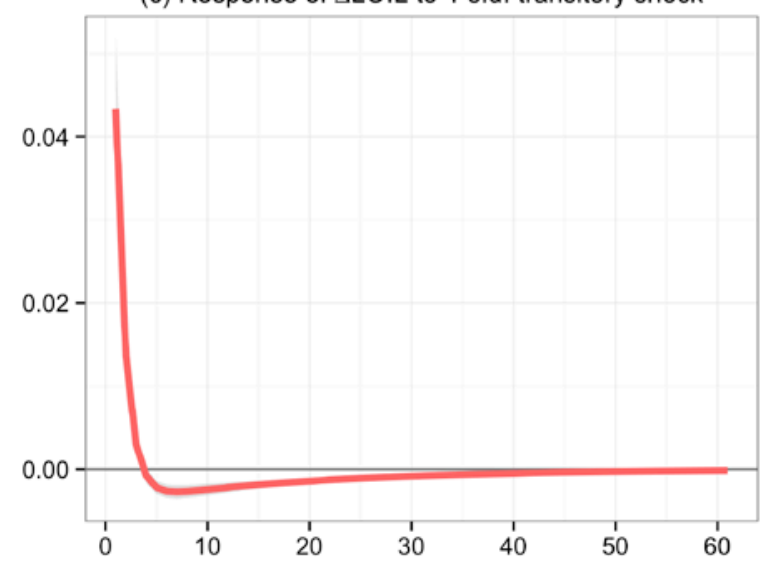

(d) Response of $\Delta$ LSP to 1 s.d. transitory shock

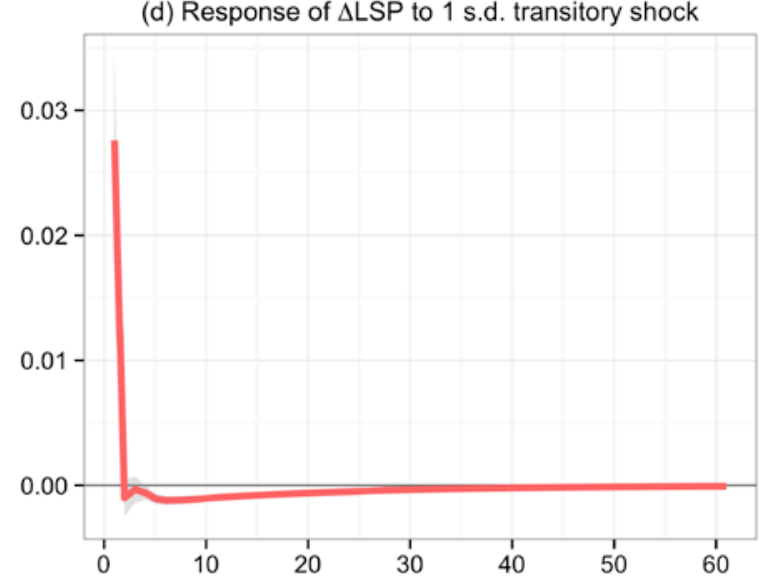

Note: See Note to Figure 6. 